Article

\title{
Quantifying the Reflectance Anisotropy Effect on Albedo Retrieval from Remotely Sensed Observations Using Archetypal BRDFs
}

\author{
Hu Zhang ${ }^{1, *}$, Ziti Jiao ${ }^{2, *}$, Lei Chen ${ }^{1}$, Yadong Dong ${ }^{2}{ }^{\circledR}$, Xiaoning Zhang ${ }^{2}$, Yi Lian ${ }^{1}$, Da Qian ${ }^{1}$ \\ and Tiejun Cui ${ }^{1}$ \\ 1 School of Geographic and Environmental Sciences, Tianjin Normal University, Tianjin 300387, China; \\ chenleii0106@126.com (L.C.); fishlice@163.com (Y.L.); qianda0915@126.com (D.Q.); tiejun_cui@163.com (T.C.) \\ 2 State Key Laboratory of Remote Sensing Science, Jointly Sponsored by Beijing Normal University and \\ Institute of Remote Sensing and Digital Earth of Chinese Academy of Sciences, Beijing 100875, China; \\ dyd@mail.bnu.edu.cn (Y.D.); xnzhang@mail.bnu.edu.cn (X.Z.) \\ * Correspondence: askzhanghu@126.com (H.Z.); jiaozt@bnu.edu.cn (Z.J.); Tel.: +86-010-5880-1730 (Z.J.)
}

Received: 23 August 2018; Accepted: 11 October 2018; Published: 13 October 2018

\begin{abstract}
The reflectance anisotropy effect on albedo retrieval was evaluated using the Moderate Resolution Imaging Spectroradiometer (MODIS) bidirectional reflectance distribution functions (BRDFs) product, and archetypal BRDFs. Shortwave-band archetypal BRDFs were established, and validated, based on the Anisotropy Flat indeX (AFX) and time series MODIS BRDF over tile h11v03. To generate surface albedo, archetypal BRDFs were used to fit simulated reflectance, based on the least squares method. Albedo was also retrieved based on the least root-mean-square-error (RMSE) method or normalized difference vegetation index (NDVI) based prior BRDF knowledge. The difference between those albedos and the MODIS albedo was used to quantify the reflectance anisotropy effect. The albedo over tile h11v03 for day 185 in 2009 was retrieved from single directional reflectance and the third archetypal BRDF. The results show that six archetypal BRDFs are sufficient to represent the reflectance anisotropy for albedo estimation. For the data used in this study, the relative uncertainty caused by reflectance anisotropy can reach up to $7.4 \%, 16.2 \%$, and $20.2 \%$ for sufficient, insufficient multi-angular and single directional observations. The intermediate archetypal BRDFs may be used to improve the albedo retrieval accuracy from insufficient or single observations with a relative uncertainty range of $8-15 \%$.
\end{abstract}

Keywords: AFX; MODIS; archetypal BRDF; NDVI; single observation

\section{Introduction}

Albedo is defined as the proportion of solar shortwave radiation $(0.25-2.5 \mu \mathrm{m})$ reflected from a surface to that incident upon it [1]. Albedo is a particularly important parameter in the land surface energy balance and Earth's radiation balance, which dictates the rate of land surface heating under different environmental conditions. It is well known that surface albedo is among the main radiative uncertainties in the Global Climate Observing System (GCOS) [2]. The absolute (relative) albedo accuracy required for climate studies is estimated to be $0.02-0.05( \pm 10 \%)$ over a range of spatial and temporal scales [3-6]. A simple calculation shows that an albedo uncertainty of $10 \%$ induces an uncertainty of approximately $5 \%$ in the net radiation, which may result in an absolute error of $20 \mathrm{~W} \mathrm{~m}^{-2}$ in the net radiation [7].

Satellite remote sensing provides a feasible way to produce large-area albedo datasets with high spatial and temporal resolutions. However, albedo inversion from remote sensing observations is also restricted by certain factors, mainly reflectance anisotropy and spare angular sampling [8]. For most 
natural surfaces, the reflection of incoming shortwave radiation is anisotropic [9]. One of the major difficulties in the quantitative retrieval of land surface characteristics from reflectance measurements results from the radiation anisotropy. The bidirectional reflectance distribution function (BRDF), which is defined as the ratio of the reflected radiance in a specified direction to the unidirectional irradiance incident on a surface [10], characterizes the anisotropy of surface reflectance. BRDFs have been widely used in the retrieval of vegetation structure and other bio-geophysical parameters [11-13]. BRDFs cannot be directly measured; however, the measured surface reflectance at various solar and observational angles enables BRDF sampling. The measurements of directional reflectance can be used as input into a numerical BRDF model, and the output is a function used to estimate the surface BRDF. Various BRDF models have been proposed by investigators [14-17]. The Ross-Thick-Li-Sparse Reciprocal (RTLSR) model is one of the most widely used BRDF models. The RTLSR BRDF model was shown to be well suited to describe surface anisotropy $[12,18]$ and was chosen in a previous study to generate the Moderate Resolution Imaging Spectroradiometer (MODIS) BRDF and albedo product [19].

Typically, sufficient angular samples and well-distributed angular sampling are needed for various BRDF models [20]. Most empirical and semi-empirical BRDF models can be inverted well with sufficient and well-distributed measurements, but problems occur in situations when sampling is sparse [18]. However, the acquisition of multi-angular measurements from most sensors is limited by the sensors' scanning configurations and the platform's orbital characteristics [21]. Remote sensing signals are usually correlated to some degree [22]. Moreover, cloud contamination reduces the number of clear-sky observations and makes the angular distribution difficult to predict. For coarse resolution satellite remote sensing data, sufficient observations can be collected by temporal composition over short time periods with the assumption that the land surface does not experience significant changes during that observational period. However, most middleand high-resolution remote sensing provides only near nadir signals. For the past two decades, BRDF/albedo estimates derived from satellite data have been produced using various kinds of low-resolution satellite sensors, such as Advanced Very High-Resolution Radiometer (AVHRR), POLarization and Directionality of the Earth's Reflectances (POLDER), MODIS, and Multi-angle Imaging Spectroradiometer (MISR) [3,12,23-26]. The operational MODIS BRDF/albedo retrieval algorithm [23] uses the RTLSR BRDF model to capture the surface reflectance directionality. A continuous global BRDF/albedo dataset has been produced at resolutions of 0.5 to $5 \mathrm{~km}$ from MODIS 16-day acquisitions since July 2000 [23]. More recently, this algorithm has been applied to correcting the diffuse light of ground multi-angular measurements [27] for linkage with other models [28], to investigate the influence of spatial resolution on the angular variation patterns of optical reflectance as retrieved from MODIS and POLDER measurements [29], and to generate the MODIS clumping index $(\mathrm{CI})$ product $[30,31]$.

Early field measurements of surface reflectance anisotropy [32-35] revealed that the characteristic BRDF shapes were associated with different homogeneous land cover classes. Linking the reflectance anisotropy to land cover or normalized difference vegetation index (NDVI), many studies have attempted to extract prior BRDF knowledge from historical MODIS BRDF products to improve the albedo retrieval accuracy from single directional reflectance [36-38]. However, one study shows that the BRDF contains little information on land cover [39]. In our previous study, we found that the Anisotropic Flat index (AFX) has the ability to indicate the character of reflectance anisotropy. The archetypal BRDF database was established for the red and near infrared bands based on the MODIS product [40]. The representativeness of these archetypal BRDFs for the reflectance anisotropy has been proven [41], and these archetypal BRDFs have been used to improve the albedo retrieval from small view-angle observations based on the least root-mean-square-error (RMSE) method [42]. Although albedo retrieved from prior BRDFs based on land cover and NDVI have generally achieved high consistency in ground observations, statistics show that land cover and NDVI are not always reliable indexes for representing reflectance anisotropy [43]. 
In the present study, we aimed to quantify the reflectance anisotropy effect on albedo retrieval from remotely sensed observations using archetypal BRDFs. Archetypal BRDFs are established for the shortwave band $(0.25-2.5 \mu \mathrm{m})$. Then, archetypal BRDFs are used to fit multi-angular or single observations to generate albedo, and the difference between these albedos and the MODIS albedo product is observed to assess the reflectance anisotropy effect on albedo retrieval. The effects of the solar zenith angle and observation noise are also considered. Finally, we investigated the improvement of NDVI-based prior BRDF knowledge in albedo retrieval and the possibility of using the intermediate archetypal BRDF to retrieve albedo from directional reflectance.

\section{Materials and Methods}

\subsection{Theoretical Basis}

The Ross-Li BRDF model is a linear combination of three basic scattering components, which represent isotropic scattering, basic turbid medium scattering and sparse vegetation scattering.

$$
R\left(\theta_{s}, \theta_{v}, \Phi, \lambda\right)=f_{\text {iso }}(\lambda)+f_{\text {vol }}(\lambda) K_{\text {vol }}\left(\theta_{s}, \theta_{v}, \Phi, \lambda\right)+f_{\text {geo }}(\lambda) K_{\text {geo }}\left(\theta_{s}, \theta_{v}, \Phi, \lambda\right),
$$

where $R$ is the surface bidirectional reflectance in wavelength $\lambda ; f_{i s o}, f_{\text {vol }}$, and $f_{\text {geo }}$ are the spectrally dependent BRDF model parameters; $K_{v o l}$ and $K_{g e o}$ are kernel functions that describe the volumetric $[15,44]$ and geometric optical $[14,19]$ scattering, respectively; and $\theta_{s}, \theta_{v}$ and $\Phi$ denote the illumination and view directions.

The kernels are simply trigonometric functions of viewing and illuminating geometrics; therefore, these kernels can be calculated in advance. In the albedo inversion procedure, sufficient multi-angular observations are applied to the model, and then, the three model parameters can be inverted [23]. The reflectance in any direction can be calculated based on the model parameters and BRDF model in the forward direction. A BRDF integral over the viewing hemisphere or both the viewing and illuminating hemispheres results in black sky albedo (BSA), or white sky albedo (WSA). The combination of these values with the fraction of direct and diffuse radiation results in an actual (or blue-sky) albedo for a specific time, such as that measured at the surface by field sensors under ambient illumination [12,45,46].

Normalizing the WSA with the isotropic parameter to remove the spectral reflectance amplitude, the new anisotropy index (AFX) can be generated [40]:

$$
\operatorname{AFX}(\lambda)=\frac{\mathrm{WSA}(\lambda)}{f_{\text {iso }}(\lambda)}=1+\frac{f_{\text {vol }}(\lambda)}{f_{\text {iso }}(\lambda)} \times 0.189184+\frac{f_{\text {geo }}(\lambda)}{f_{\text {iso }}(\lambda)} \times(-1.377622),
$$

where the constant values of 0.189184 and -1.377622 are the integral of the Ross-Thick kernel and the Li-Sparse Reciprocal kernel in the viewing and illuminating hemispheres, respectively.

The AFX is related to the variability of the BRDF shapes of land surface. A previous study [40] showed that when geometric scattering is dominant (dome-shaped BRDF shapes), the AFX value is less than 1.0, whereas when volumetric scattering is dominant (bowl-shaped BRDF shapes), the AFX value is greater than 1.0. When the two scatterings are comparable and counteract each other (relatively Lambertian BRDF shapes), the AFX value is close to 1.

\subsection{MODIS BRDF Product and Simulated Observations}

The operational MODIS BRDF algorithm for the MODIS BRDF/albedo product is based on the RTLSR BRDF model and an adequate angular sample of the cloud-cleared, atmospherically corrected surface reflectance available for each location over a 16-day period [23]. The accuracy of the high-quality MODIS albedo values at local solar noon (LSN) meet an absolute accuracy requirement of 0.05 for validation sites with homogeneous cover conditions [20,47-49]. These datasets have been widely 
used in reflectance anisotropy studies $[36,37,40]$. To obtain precise and consistent results, only the high-quality MODIS BRDF product [20] is considered during the research process.

In this study, MODIS tile h11v03 is used as the study area. Figure 1 shows the land cover map and the maximum-value composite NDVI of year 2011 over the study area. Evergreen Needleleaf forest, Mixed forest and Croplands are the main land cover types in this area. The NDVI values are mainly concentrated within the range of $0.6 \sim 0.9$, and the white gaps area in Figure $1 \mathrm{~b}$ is due to a lack of high-quality MODIS NDVI product. The study area contains abundant types of reflectance anisotropy and can provide enough experimental data for this study. The Version 005 MODIS BRDF / Albedo product (MCD43A1 and MCD43A2) of tile h11v03 during days 153 to 241 in 2009 and 2010 is used to establish the archetypal BRDFs. The MODIS BRDF data can be classified into different clusters in terms of similar AFX values. The BRDF parameters within each cluster can be averaged to represent the corresponding cluster. These generalized BRDF shapes are then referred to as the BRDF archetypes [40]. The representativeness of these archetypal BRDFs is verified using the MODIS BRDF data of tile h11v03 during the same period in 2011 and 2012.

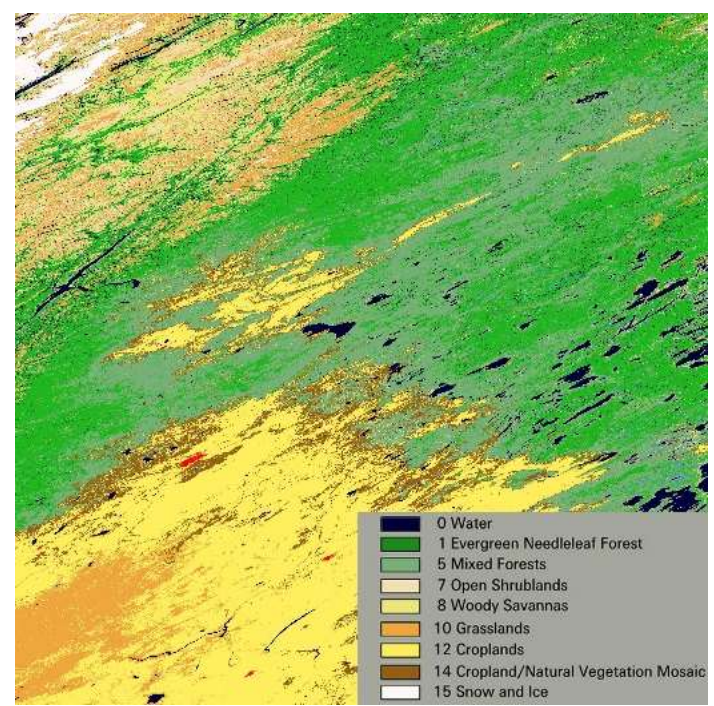

(a)

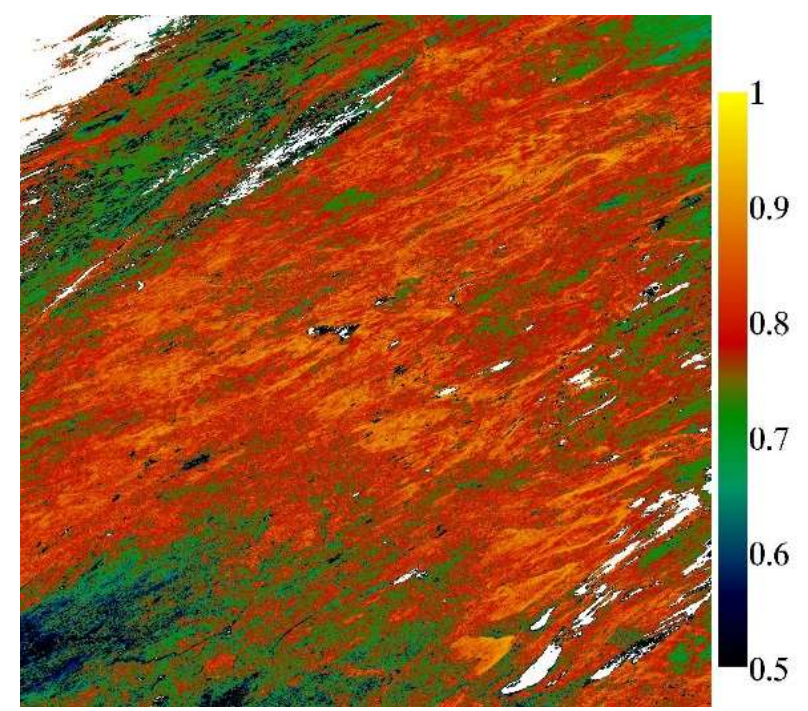

(b)

Figure 1. (a) Land cover map and, (b) maximum-value composite normalized difference vegetation index (NDVI) of year 2011 over tile h11v03.

The simulated multi-angular observations or single directional reflectance are based on the RTLSR BRDF model and the MODIS BRDF product of tile h11v03 during days 153 to 241 in 2012. To present a convincing and exhaustive result, the MODIS BRDF data are first classified into several classes according to AFX, and finally, 1 million samples are chosen for each BRDF archetype class. According to the number of observations and the distribution of angular sampling, sufficient and insufficient observations are used. The distribution of sufficient observations used in this study is shown in Figure 2. These observations are extracted from the MODIS reflectance product (MOD09G and MYD09GA) during days 201 to 216 in 2012 over tile h11v03, and the solar zenith angle is approximately $40^{\circ}$. These angular samples meet the requirements of the MODIS full inversion method with 28 observations and a weight of determination (WOD) value of 0.147 [20]. The six observations with the largest view zenith of $20^{\circ}$ (the red circle) are used as the insufficient multi-angular observations. Three types of single directional reflectances are considered in this study: (1) Nadir reflectance; (2) directional reflectance with a viewing zenith angle of $30^{\circ}$ in the forward direction; and (3) directional reflectance in the backward direction in the principal plane at a solar zenith angle of $40^{\circ}$. To ensure the reliability of the results, random noise, ranging from $-10 \%$ to $10 \%$, is added to the simulated observations. 


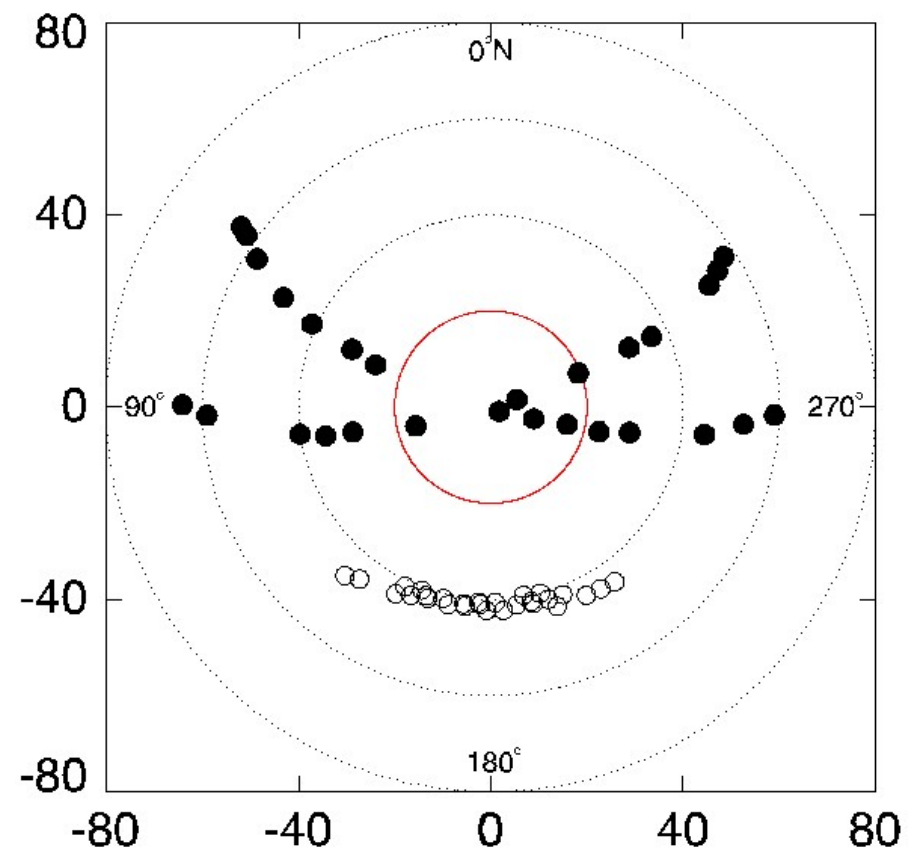

Figure 2. Distribution of sufficient multi-angular observations. The radius represents the zenith angle with an interval of $20^{\circ}$, and the polar angle represents the azimuth angle. The filled and open circles refer to locations of the observations and the sun. The red circle represents the zenith angle of $20^{\circ}$.

\subsection{Extraction of the Archetypal BRDF from the MODIS BRDF Product}

Based on the MODIS BRDF product and AFX, the archetypal BRDFs for the red and near infrared bands were established in Reference [40]. For further study of the reflectance anisotropy effect on albedo in the shortwave band, we use the same approach to establish the archetypal BRDFs for the shortwave band. First, the AFX value of each pixel in the shortwave band is calculated using Equation (2). Second, the AFX values and associated MODIS BRDF model parameters are classified to generate different BRDF classes using the ISODATA (iterative self-organizing data analysis technique) clustering algorithm. To generate archetypal BRDFs, the with-class model parameters first need to be normalized with isotropic parameters to remove the spectral reflectance amplitude effect [40], and then, the parameters are averaged to represent the archetypal BRDF model parameters for that class. Third, to determine the number of classifications, the MODIS BRDF product is classified into 1 to 10 categories according to the AFX values, and the archetypal BRDFs are used to fit the corresponding within-class MODIS BRDF according to the simulated reflectance using the least squares approach. The simulated reflectance has a maximum view zenith angle of $60^{\circ}$ with a $10^{\circ}$ interval for the viewing zenith angle and a $45^{\circ}$ interval for the viewing azimuth angle. The number of the most appropriate archetypal BRDFs is confirmed through the change in the root mean square error (RMSE). Finally, the extent to which the BRDF archetypes are representative of BRDF archetypes to the reflectance anisotropy is verified using time series of MODIS BRDF data.

\subsection{Albedo from Prior BRDF and Limited Observations}

Where the observations are sparsely sampled, including the limit of measuring only a single observation, we can improve the albedo retrieval accuracy using prior BRDF knowledge [22]. In this study, prior BRDF knowledge refers to the archetypal BRDFs and NDVI-based BRDF extracted from the MODIS BRDF data. Assuming that the prior anisotropy estimate of the pixel BRDF is known, we may predict the probable pixel BRDF under the observed reflectances and hence calculate the albedos. During this process, the prior BRDF parameters $\left(F_{i s o}, F_{v o l}\right.$ and $\left.F_{g e o}\right)$ are applied to the RTLSR model to calculate the simulated reflectance $\left(\rho^{\prime}\right)$, which has the same observation geometry as the 
observed reflectance $(\rho)$. The value of $a$, which can adjust and fit the prior archetypal BRDF to the observation best, can be calculated by using the least squares method $[38,50]$.

$$
a=\left\{\begin{array}{c}
\sum_{i=1}^{n} \rho_{i} \rho^{\prime}{ }_{i} / \sum_{i=1}^{n}\left(\rho_{i}^{\prime}\right)^{2}, \quad n>1 \\
\frac{\rho}{\rho^{\prime}}, \quad n=1
\end{array},\right.
$$

where $n$ refers to the number of observations, and $\rho$ and $\rho^{\prime}$ are is the observed and the simulated reflectance, respectively.

The fitting error can be expressed as follows:

$$
\text { RMSE }=\sqrt{\frac{\sum_{i=1}^{n}\left(a \rho_{i}^{\prime}-\rho_{i}\right)}{n-1} .}
$$

Then, the surface albedo can be estimated according to the RTLSR BRDF model.

$$
\alpha_{\text {blue }}=a\left[f_{\text {dif }} \sum_{i=1}^{3} F_{i} H_{k}+\left(1-f_{\text {dif }}\right) \sum_{i=1}^{3} F_{i} h_{k}(\theta)\right],
$$

where $\alpha_{b l u e}$ is the simulated albedo under actual atmospheric conditions, $f_{\text {dif }}$ is the diffuse skylight ratio, $F$ is the prior BRDF parameters, $h_{k}$ and $H_{k}$ are the directional-hemispherical and bi-hemispherical integrals of the BRDF model kernels, and $\theta$ is the solar zenith angle. For our study region, we used the atmospheric optical depth at $550 \mathrm{~nm}$ based on MODIS Level 2 aerosol products to derive the diffuse skylight fraction for the shortwave. In the following section of this study, the MODIS albedo is the blue-sky albedo $\left(\alpha_{\text {blue }}\right)$.

\subsection{Reflectance Anisotropy Effect}

In the fitting process mentioned above, the prior BRDF knowledge and estimated BRDF have the same AFX value; that is, both BRDFs have the same reflectance anisotropy. The archetypal BRDFs represent various surface reflectance anisotropies; therefore, the differences between albedos retrieved based on different archetypal BRDFs and the same observations can indicate the reflectance anisotropy effect on albedo retrieval. For the single directional reflectance, the reflectance is directly taken as albedo according to the Lambertian assumption. The difference between these albedos and the MODIS albedo can be used to quantitatively evaluate the reflectance anisotropy effect on albedo retrieval.

Three metrics are used to quantify the deviation between albedos retrieved from prior BRDFs and the MODIS albedo: (1) Bias, (2) absolute $R M S E_{A}$, and (3) relative $R M S E_{R}$. These metrics were used to quantify the accuracy, and the absolute and relative uncertainties [51].

$$
\begin{gathered}
\text { Bias }=\frac{1}{N} \sum_{j=1}^{N}\left(\text { Albedo }_{P j}-\text { Albedo }_{M j}\right), \\
\operatorname{RMSE}_{A}=\sqrt{\frac{1}{N-1} \sum_{j=1}^{N}\left(\text { Albedo }_{P}-\text { Albedo }_{M}\right)^{2}}, \\
\operatorname{RMSE}_{R}=\frac{\text { RMSE }_{A}}{\text { Albedo }_{M}},
\end{gathered}
$$

where subscript $j$ refers to each pixel of the experimental data used in this study, $N$ refers to the number of valid pixels used for comparison, Albedo $o_{p}$ is the albedo retrieval from prior archetypal BRDFs, and $A l b e d o_{M}$ is the mean value of all MODIS albedos. To make the results comparable, we consider the same experimental data throughout this study. 


\section{Results}

The archetypal BRDFs for the shortwave band are first established based on the MODIS BRDF product, and the representativeness of these archetypal BRDFs was evaluated according to other MODIS BRDF products. Next, these archetypal BRDFs and other kinds of prior BRDF knowledge are used to fit the simulated observations (sufficient, insufficient and nadir only), and the albedos are eventually obtained. Finally, the difference between these albedo products and the MODIS albedo products is used to show whether the archetypal BRDF represents the real surface reflectance anisotropy. The effects of the solar zenith angle and observational noise are also investigated.

\subsection{BRDF Archetype and Validation}

\subsubsection{Archetypal Shortwave BRDFs}

Similar to a previous study [40], the present study uses the fitting RMSE to determine the best number of archetypal BRDFs. The changes in the mean RMSE with an increasing number of classes are shown in Figure 3. The increase in the number of classes results in a gradual lowering of RMSE. Considering the conciseness and redundancy of archetypal BRDFs, 6 archetypal BRDFs, which account for more than $90 \%$ of the total fit-RMSE, are sufficient to describe the surface reflectance anisotropy for albedo retrieval. Table 1 shows the model parameters and AFX range for the 6 archetypal BRDFs, and Figure 4 shows the BRDF shapes in the hemisphere at a solar zenith angle of $30^{\circ}$. This figure is drawn by a visualization tool provided in Reference [52]. With the archetypal BRDFs changing from No. 1 to No. 6, the value of $F_{v o l}$ increases while the value of $F_{\text {geo }}$ decreases; that is, the volumetric scattering gradually increases while the geometric scattering gradually decreases. In addition, the BRDF shape changes from dome-shaped to bowl-shaped.

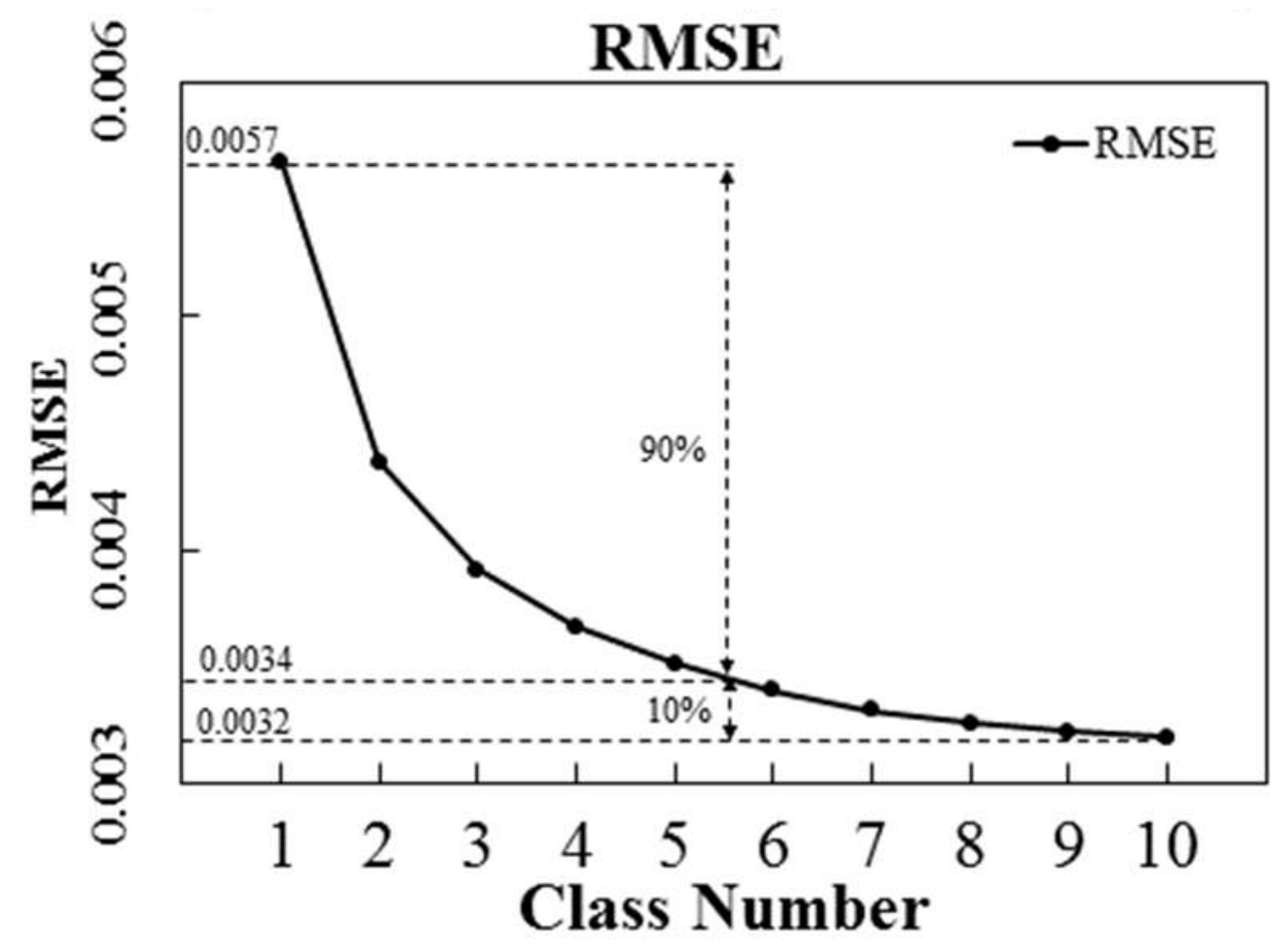

Figure 3. Fit-RMSEs (root-mean-square-errors) against the number of archetypal bidirectional reflectance distribution functions (BRDFs) (from 1 to 10). 


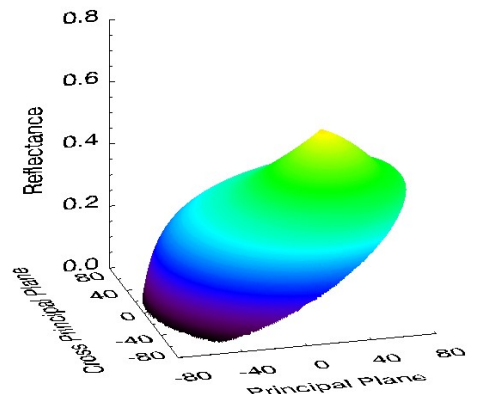

(a)

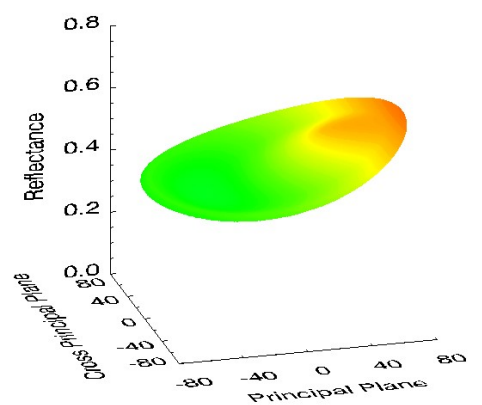

(d)

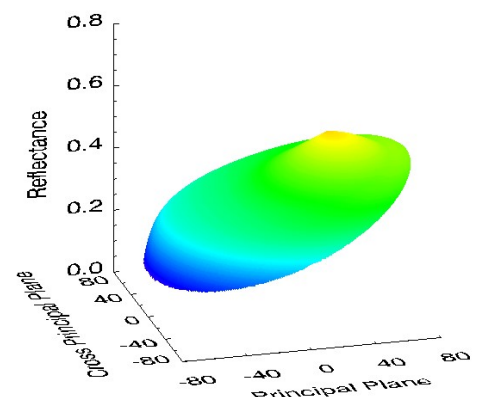

(b)

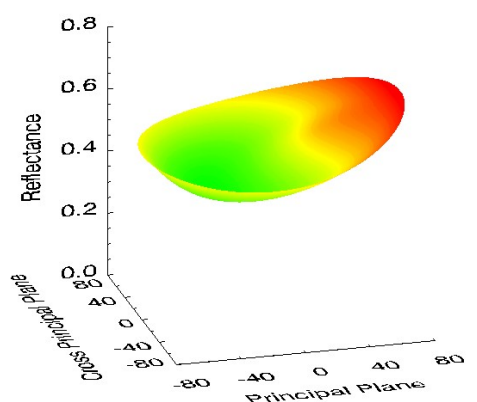

(e)

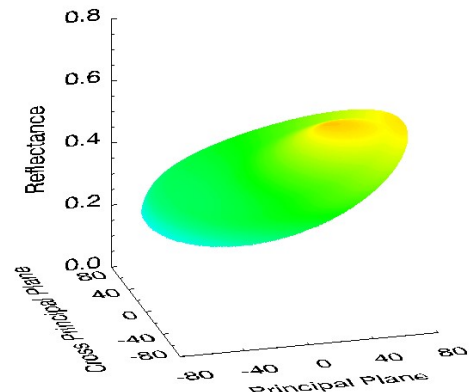

(c)

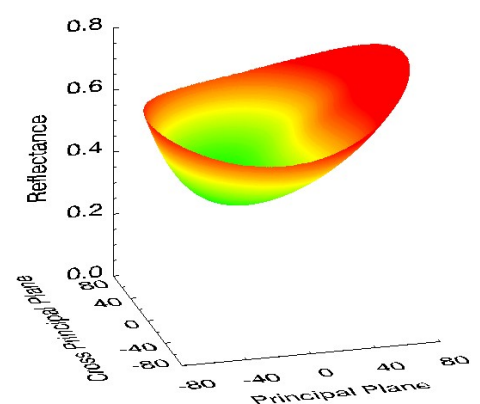

(f)

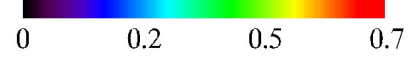

Figure 4. Three-dimensional BRDF shapes of $6 \mathrm{BRDF}$ archetypes at a solar zenith angle of $30^{\circ}$ in the shortwave band. (a-f) refer to the archetypal BRDF Nos. 1 to 6 . For the bottom coordinate plane, the radius represents the zenith angle, and the polar angle represents the azimuth angle. The BRDF values are plotted on the vertical axis.

Table 1. Anisotropy Flat indeX (AFX) range and normalized BRDF parameters of six archetypal BRDFs for the Moderate Resolution Imaging Spectroradiometer (MODIS) shortwave band.

\begin{tabular}{ccccc}
\hline Class & AFX Range & $\boldsymbol{F}_{\text {iso }}$ & $\boldsymbol{F}_{\text {vol }}$ & $\boldsymbol{F}_{\text {geo }}$ \\
\hline No. 1 & {$[0.5,0.78]$} & 0.5 & 0.1392 & 0.1289 \\
No. 2 & $(0.78,0.90]$ & 0.5 & 0.2442 & 0.0892 \\
No. 3 & $(0.9,1.0]$ & 0.5 & 0.3263 & 0.0620 \\
No. 4 & $(1.0,1.09]$ & 0.5 & 0.3970 & 0.0392 \\
No. 5 & $(1.09,1.2]$ & 0.5 & 0.4927 & 0.0179 \\
No. 6 & $(1.2,1.7]$ & 0.5 & 0.7669 & 0.0074 \\
\hline
\end{tabular}

\subsubsection{Accuracy Evaluation}

Following the method used in the earlier study [43], the validation data are first classified into 6 classes according to the AFX range of each BRDF archetype class. Then, the simulated multi-angular observations (same as Section 2.3) of each pixel are used to adjust the corresponding archetypal BRDF based on the least squares method. The extent to which the BRDF archetypes are representative of BRDF archetypes to the reflectance anisotropy is illustrated by the consistency between the MODIS BRDF and simulated BRDF. The degree of similarity between the MODIS reflectance and adjusted archetype reflectance in the same direction is actually used to evaluate the consistency.

Figure 5 shows the comparison of two kinds of reflectance in the hotspot direction at solar zenith angles of $30^{\circ}$ and $45^{\circ}$. Although the difference in the two reflectances shows a slight increase at a large solar zenith angle, almost all pixels are located along a 1:1 line and show high consistency with an $R M S E_{A}$ of less than 0.015 . The degree of similarity between the archetypal BRDFs and MODIS BRDF within the corresponding BRDF archetype class can be indirectly illustrated by the $R M S E_{A}$ of the two kinds of reflectance. Figure 6 shows the distribution of $R M S E_{A}$ in the viewing hemisphere 
at solar zenith angles of $30^{\circ}$ and $45^{\circ}$. The dark points in Figure 6 indicate the hotspot direction. The $R M S E_{A}$ values are usually relatively large around the hotspot and at large viewing zenith angle areas close to the principal plane. Additionally, the $R M S E_{A}$ shows a tendency to grow with increasing solar zenith angle. These results indicate that the archetypal BRDFs can match the corresponding MODIS BRDF well, particularly when the solar zenith angle is small and near the cross-principal plane area. The 6 archetypal BRDFs can cover various reflectance anisotropy values for albedo retrieval in the shortwave band.

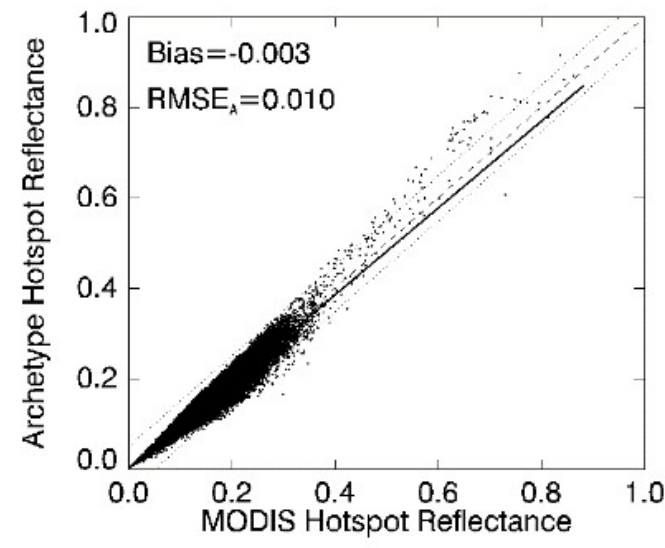

(a)

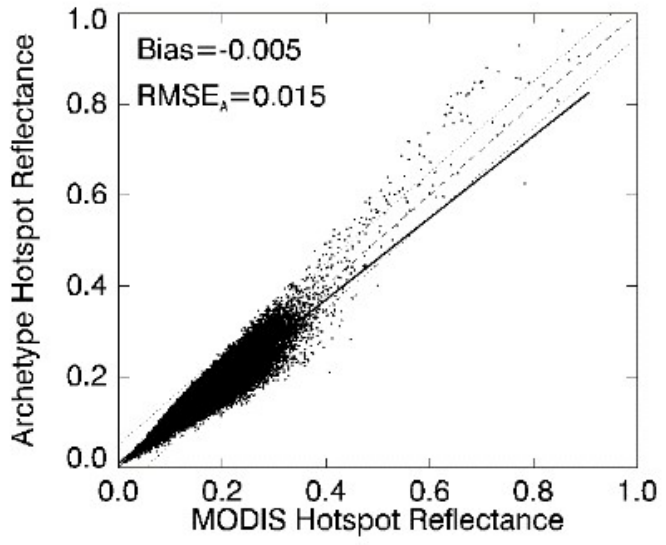

(b)

Figure 5. Comparison of MODIS reflectance and the reflectance of corresponding archetypal BRDFs in the hotspot direction at solar zenith angles of (a) $30^{\circ}$, and (b) $45^{\circ}$.

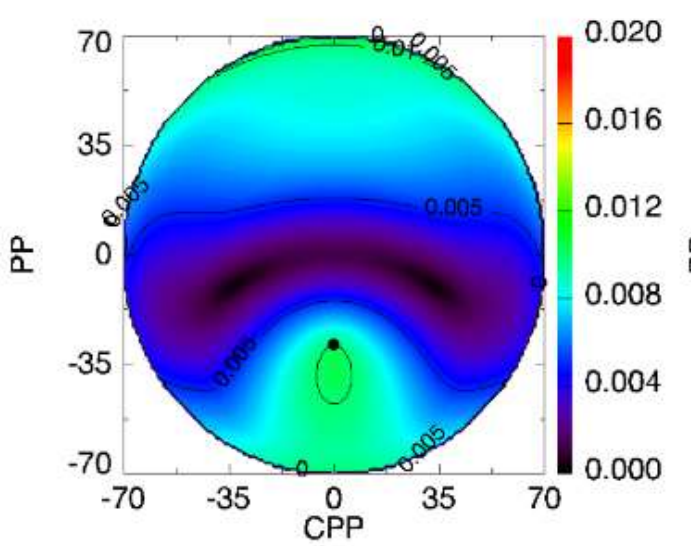

(a)

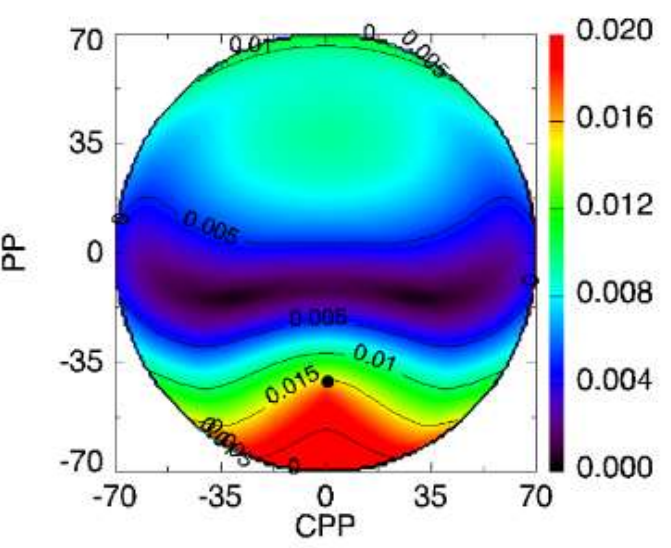

(b)

Figure 6. The distribution of RMSE between the MODIS BRDF and corresponding archetypal BRDFs over the hemisphere at solar zenith angles of (a) $30^{\circ}$, and (b) $45^{\circ}$. The radius represents the zenith angle, and the polar angle represents the azimuth angle.

\subsection{BRDF Effect on Albedo Retrieval}

The effect of reflectance anisotropy on albedo retrieval is closely related to the shape of surface BRDF, the number and the spatial distribution of the observations. The 6 archetypal BRDFs in the shortwave band represent different reflectance anisotropies. The observations can be simulated based on the MODIS BRDF and kernel driven BRDF model. These archetypal BRDFs are used to fit the observations according to the least squares method and are eventually used to obtain the surface albedos. The difference between these albedos and the MODIS albedo products can be used to indicate the reflectance anisotropy effect on albedo retrieval from the directional reflectance. 


\subsubsection{Multi-Angular Observations}

Figure 7 shows a comparison of the MODIS albedo and albedos retrieved from different archetypal BRDFs and either sufficient observations or insufficient observations. The red, green and blue annotations represent the result of samples that belong to BRDF archetype classes Nos. 1, 3, and 6, respectively, and the black annotation represents the results of all data.

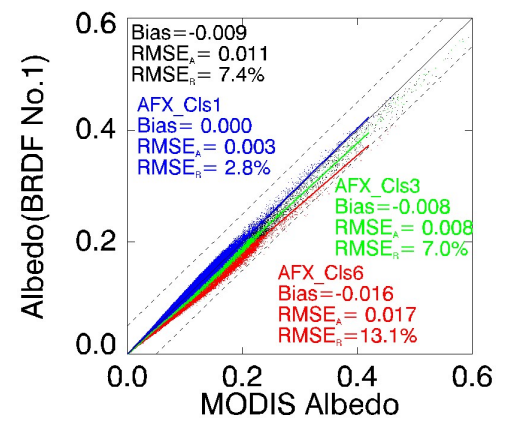

(a1)

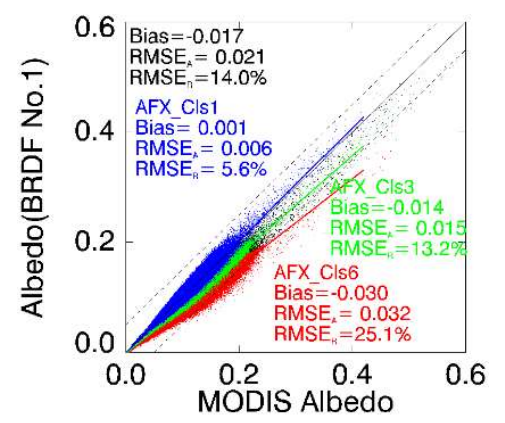

(b1)

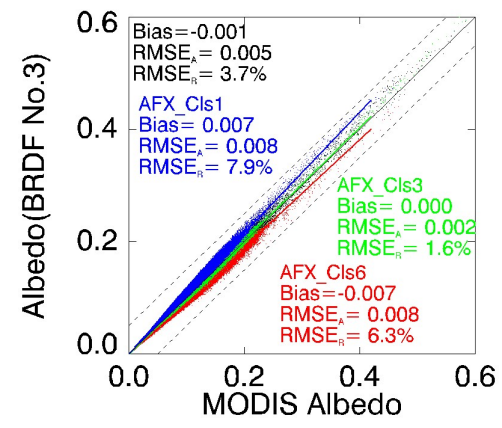

(a2)

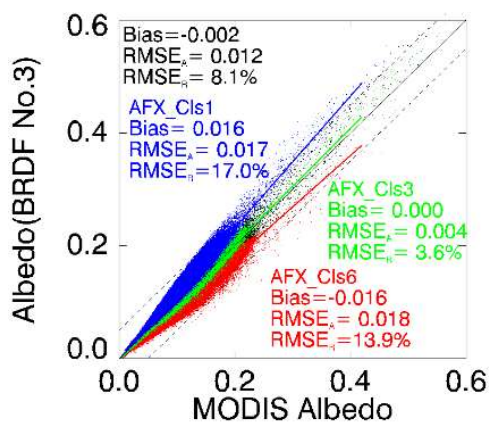

(b2)

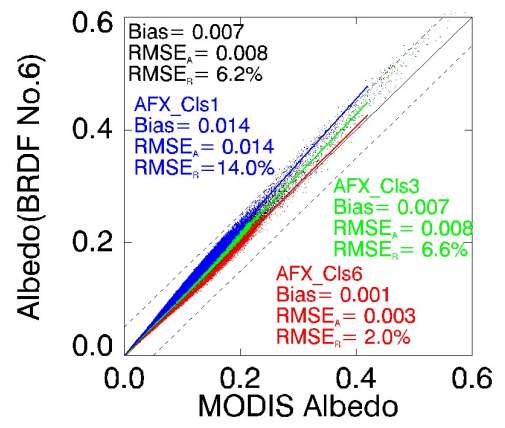

(a3)

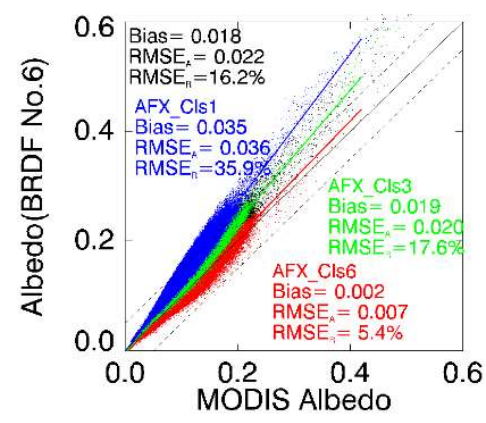

(b3)

Figure 7. Comparison of MODIS albedo with albedos retrieved from different archetypal BRDFs and sufficient (a1-a3), or insufficient (b1-b3), observations with a solar zenith angle of approximately $40^{\circ}$. $(\mathbf{a} 1, \mathbf{b 1}),(\mathbf{a} 2, \mathbf{b} 2)$ and $(\mathbf{a} 3, \mathbf{b 3})$ refer to albedo retrieved from archetypal BRDF Nos. 1, 3, and 6, respectively.

Because the data contain various reflectance anisotropy characteristics, the albedo based on one specific archetypal BRDF may be inappropriate and may introduce some errors. The MODIS albedo and albedos retrieved from any archetypal BRDFs agree well for the sufficient observations, with very good uncertainty values of under 0.011 for $R M S E_{A}$ and $7.4 \%$ for $R M S E_{R}$. We observe a high discrete degree when applying the archetypal BRDFs to the insufficient observations; the absolute and relative uncertainties doubled, and the accuracy appeared to decrease. In particular, when the samples belonging to the archetypal BRDF class are taken as prior BRDF knowledge, the retrieved result has the highest consistency with the MODIS albedo. The relative uncertainties are approximately $2 \%$ and $5 \%$, for sufficient and insufficient observations, respectively. When the real reflectance anisotropy of the sample shows a large difference from the prior archetypal BRDF (i.e., the archetypal BRDF No. 6 is used to fit samples that belong to BRDF archetype class No. 1), the retrieved albedo has a lower accuracy. The maximum relative uncertainties can reach up to $14 \%$ and $35.9 \%$ for sufficient and insufficient observations, respectively. The archetypal BRDF No. 1 tends to underestimate the albedo, while the archetypal BRDF No. 6 tends to overestimate the albedo. However, the intermediate archetypal BRDFs (BRDF Nos. 3 and 4) are the most likely to obtain a reasonable result, with relative uncertainties of $3.7 \%$ and $8.1 \%$ for sufficient or insufficient observations, respectively.

The six archetypal BRDFs are used to fit the multi-angular observations according to least squares method. The archetypal BRDF with the least fitting error is chosen as the prior BRDF for the pixels, and the corresponding albedo is taken as the most probable albedo. This method is known as the least RMSE method [41]. Figure 8 shows the albedo retrieved based on the least RMSE method and 
sufficient or insufficient observations. When the observations are sufficient, the albedo retrieved from the least RMSE method has the highest consistency with the MODIS albedo. When the observations are insufficient, the albedo retrieved based on the least RMSE method shows a high discrete degree, with a relative uncertainty of $13.4 \%$, because the observations within the small zenith area cannot effectively indicate the shape of reflectance anisotropy in the entire hemisphere. However, the accuracy of this albedo is still nearly equivalent to the albedo based on the archetypal BRDF No. 3.

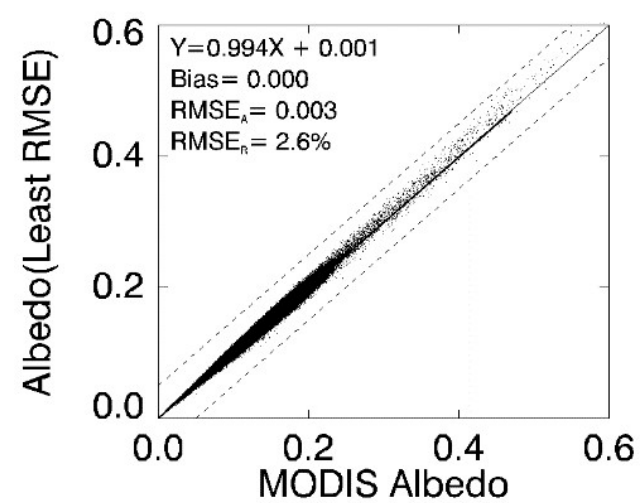

(a)

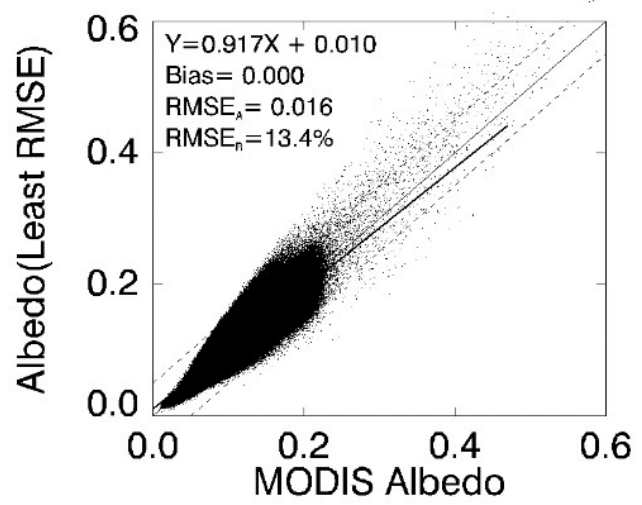

(b)

Figure 8. Comparison of MODIS albedo with albedos retrieved from sufficient (a) and insufficient (b) observations based on archetypal BRDFs and the least RMSE method.

Figure 9 shows the distribution of the absolute difference $\left(\right.$ Albedo $_{P}$-Albedo $\left.M\right)$ between the MODIS albedo and the albedos retrieved from archetypal BRDFs. As above, with the prior BRDFs changing from archetypal BRDF No. 1 to 6 , the retrieved albedo gradually increases. Compared with the sufficient observations, the albedo retrieved from the insufficient observations shows a high discrete degree. However, because the albedo is the integration of BRDF over the whole hemisphere, due to the restriction of prior knowledge to the inversion BRDF, the retrieved albedo from the intermediate prior archetypal BRDFs (No. 3 or 4) or the least RMSE method and insufficient multi-angular observations can basically meet the accuracy requirements, with almost all the samples having an absolute difference of within 0.04 .

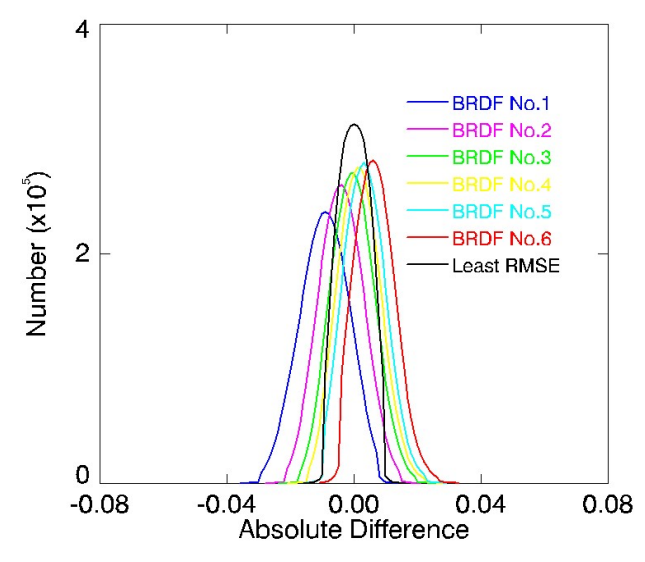

(a)

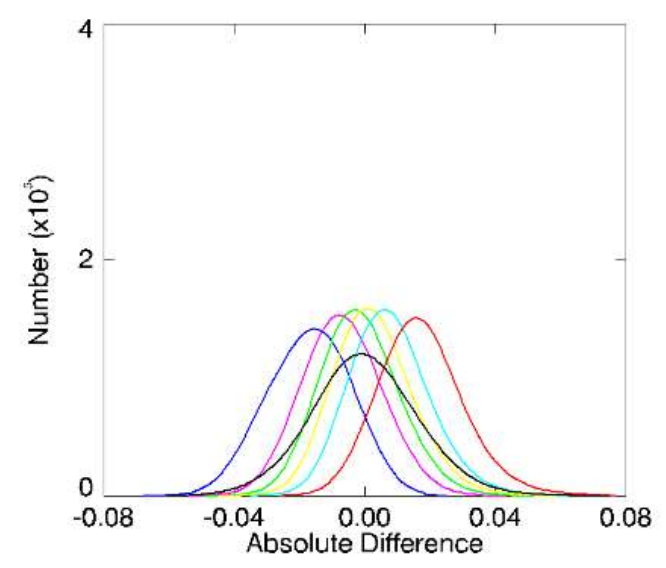

(b)

Figure 9. The distribution of the absolute difference between the MODIS albedo and albedo retrieved from the archetypal BRDFs with (a) sufficient observations, and (b) insufficient observations. The blue, purple, green, yellow, cyan and red lines indicate the results of archetypal BRDF Nos. 1 through 6, respectively. The black line indicates the results of the least RMSE method. 
To explore the effects of the solar zenith angle on the fitting process, we investigate the distribution of the absolute difference between the MODIS albedo and albedos retrieved from archetypal BRDFs (Nos. 1, 3 and 6) and sufficient or insufficient observations under various solar zenith angles, as shown in Figure 10. Different colors represent the percentages of corresponding absolute difference. The results indicate that archetypal BRDF No. 1 tends to underestimate albedo, while archetypal BRDF No. 6 tends to overestimate albedo, and archetypal BRDF No. 3 tends to obtain a reasonable result. The distribution of the absolute difference explains that the effect of the solar zenith on the albedo retrieval is more significant when the solar zenith angle is small (less than approximately $30^{\circ}$ ). The phenomenon may be partly due to the hotspot effect of the reflectance anisotropy, because the multi-angular observations are close to the hotspot direction. With increasing solar zenith angle, the impact gradually decreases. The effect of noise is also explored, because the least squares method is able to eliminate the influence of random noise in multi-angular observations, and there are no significant changes in albedo under different random noise levels.

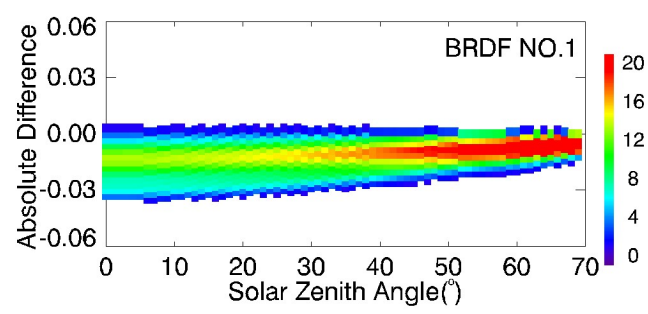

(a1)

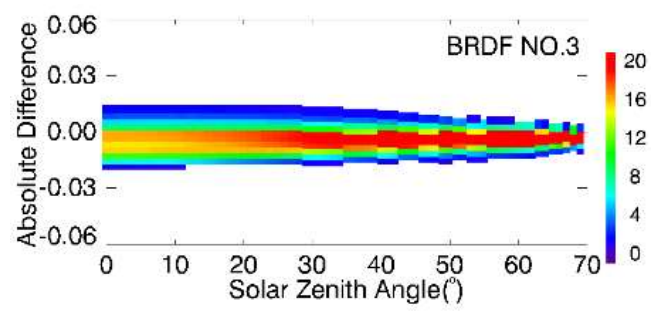

(a2)

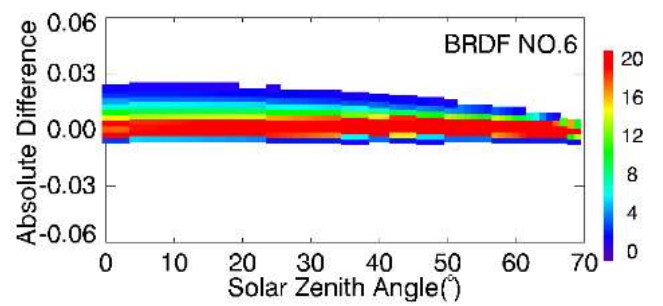

(a3)

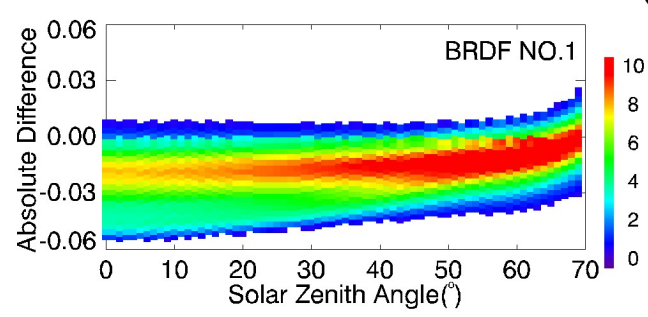

(b1)

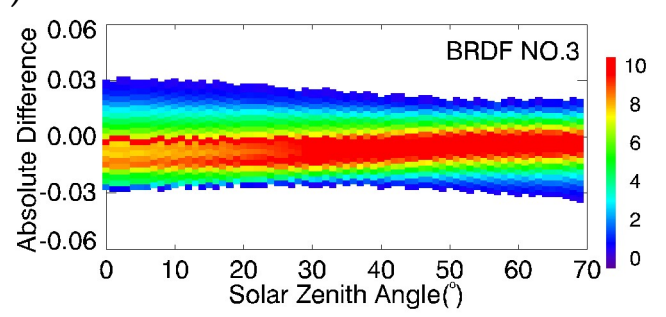

(b2)

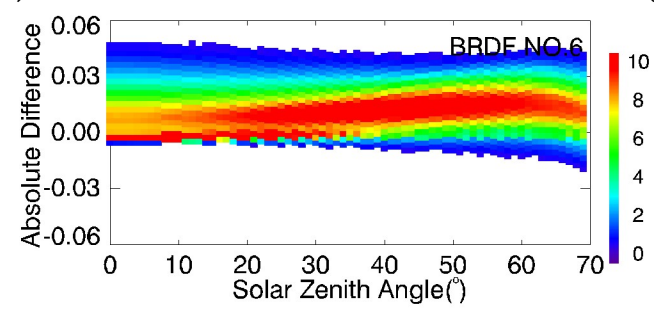

(b3)

Figure 10. The absolute difference distribution between the MODIS albedo and albedos retrieved from different archetypal BRDFs, and (a1-a3) sufficient, or (b1-b3) insufficient, observations under various solar zenith angles. The albedo is retrieved from archetypal BRDF Nos. (a1,b1) 1, (a2,b2) 3 and $(\mathbf{a} 3, \mathrm{b3}) 6$. 


\subsubsection{Single Observation}

\section{Lambertian Assumption}

Nadir reflectance was often used as the surface albedo under the assumption of Lambertian reflectance [3,53]. Figure 11 shows the absolute difference between the simulated nadir reflectance and albedo under different solar zenith angles. This result is based on the MODIS BRDF data of tile h11v03 from 2008 day 201. The MODIS BRDF data are classified according to the AFX range of archetypal BRDFs, and the mean relative difference between the nadir reflectance and MODIS albedo within each archetypal BRDF class is used to describe the effects of the Lambertian assumption. The different colors represent the six BRDF archetype classes. The effect of the Lambertian assumption on the albedo depends on the solar zenith angle and surface reflectance anisotropy. When the solar zenith angle is small $\left(<30^{\circ}\right)$, the nadir reflectance of the pixels with a strong geometric scattering usually overestimates the ground albedo, and while the solar zenith angle is large $\left(>50^{\circ}\right)$, the nadir reflectance of the pixels with a strong volumetric scattering usually underestimate albedo. The relative difference caused by the Lambertian assumption ranges from $-40 \%$ to $50 \%$. The large difference in the small solar zenith angle is mainly caused by the hotspot in the BRDF model, since the archetypal BRDF No. 1 has a strong hotspot effect and results in a dome BRDF shape, whereas archetypal BRDF No. 6 has a weak hotspot effect and results in a bowl BRDF shape.

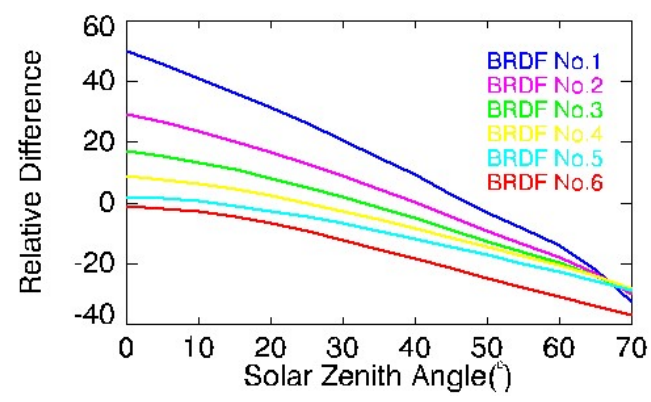

Figure 11. The relative difference between nadir reflectance and MODIS albedo under different BRDF archetype classes at various solar zenith angles.

Many remote sensing observations have a non-nadir viewing geometry. Figure 12 shows the relative difference between the MODIS albedo and directional reflectance in the viewing hemisphere under various surface reflectance anisotropies based on the archetypal BRDFs and MODIS BRDF data. When the surface reflectance anisotropy is significant (BRDF archetype class No. 1 or 6), the relative difference can be $50 \%$ or $-30 \%$ around the hotspot and dark spot areas, respectively. The maximum relative difference is still greater than $\pm 15 \%$, even for the homogeneous BRDF archetype classes No. 3 and 4 . The results indicate that the reflectance anisotropy must be considered for accurate albedo retrieval from a directional observation.

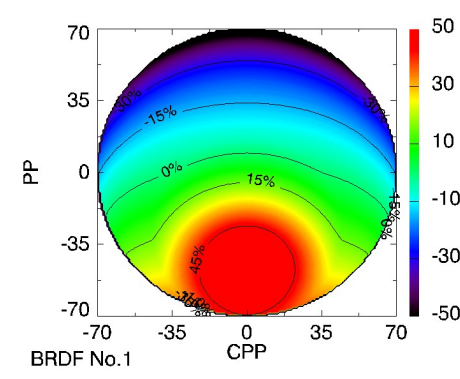

(a)

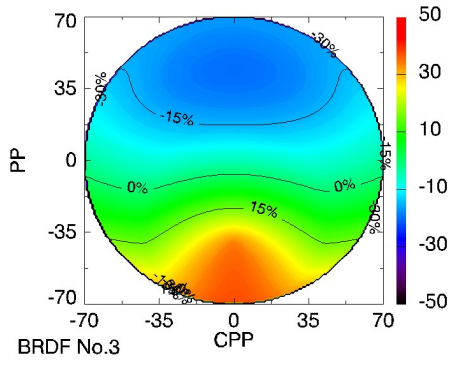

(b)

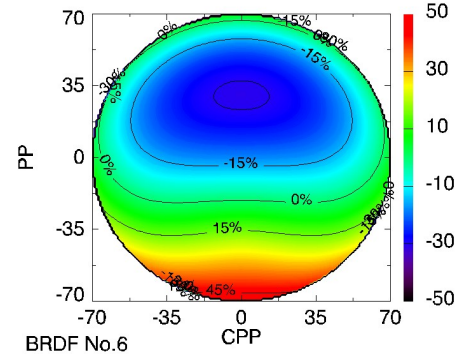

(c)

Figure 12. Relative difference between MODIS albedo and reflectance in the viewing hemisphere under (a) archetypal BRDF No. 1, (b) No. 3 and (c) No. 6 at a solar zenith angle of $40^{\circ}$. 
Albedo from Single Reflectance

Similar to the previous method, archetypal BRDFs are taken as prior knowledge to fit the single nadir reflectance and generate the albedo in the sequence. Figure 13 shows a comparison of the MODIS albedo with single nadir reflectance-based albedos. When the appropriate archetypal BRDF is used to calculate the albedo, the relative uncertainty is approximately $6-8 \%$. If the inappropriate archetypal BRDF is used, the relative uncertainty can reach up to $38.3 \%$.

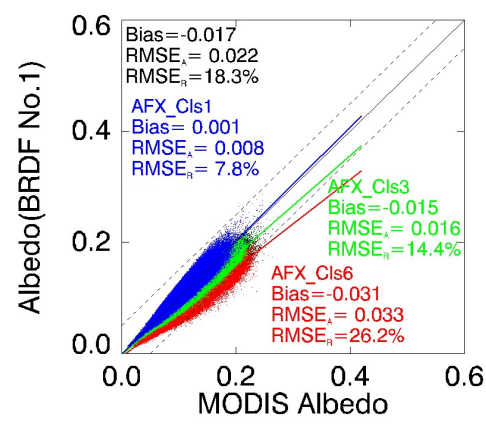

(a)

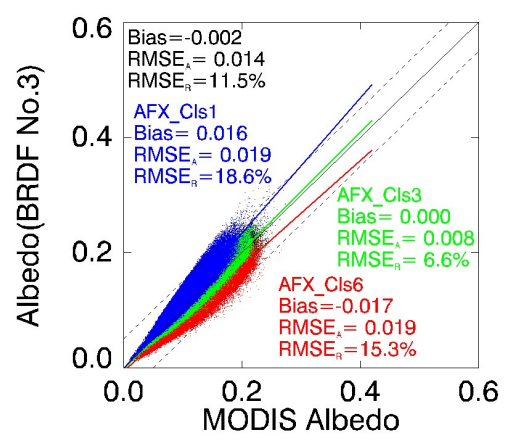

(b)

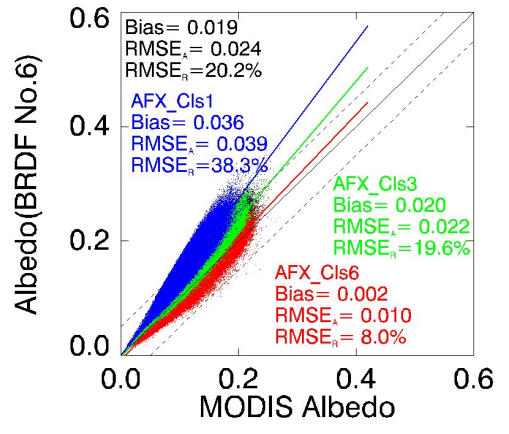

(c)

Figure 13. Comparison of MODIS albedo with albedo retrieved from archetypal BRDF No. (a) 1, (b) 3 , and (c) 6 , and nadir reflectance at a solar zenith angle of $40^{\circ}$.

For comparison, another prior BRDF knowledge is extracted from the data based on NDVI (MOD13A2). The experimental MODIS BRDF data are classified according to NDVI. The mean value of the MODIS BRDF with a 0.1 NDVI interval is taken as prior knowledge. The prior knowledge BRDF shapes in the principal plan for this prior knowledge are shown in Figure 14. $F_{v o l}$ and $F_{g e o}$ refer to the normalized BRDF parameters, and $F_{i s o}$ is equal to 0.5. Due to the coarse resolution, the MODIS pixels are usually mixed. A previous study demonstrated that MODIS data with similar NDVI values contain various reflectance anisotropies, especially for forest areas with complex structures [43]. The statistical results in Table 2 show that the prior BRDF model parameters extracted from various NDVI ranges are broadly similar. This result shows that the NDVI may not provide additional information to extract prior BRDF knowledge from historical MODIS BRDF data.

Table 2. Prior BRDF model parameters for different NDVI ranges.

\begin{tabular}{cccc}
\hline NDVI Range & $\boldsymbol{F}_{\text {iso }}$ & $\boldsymbol{F}_{\text {vol }}$ & $\boldsymbol{F}_{\text {geo }}$ \\
\hline$[0.1 \sim 0.2]$ & 0.5 & 0.499 & 0.086 \\
$(0.2 \sim 0.3]$ & 0.5 & 0.482 & 0.081 \\
$(0.3 \sim 0.4]$ & 0.5 & 0.484 & 0.060 \\
$(0.4 \sim 0.5]$ & 0.5 & 0.469 & 0.053 \\
$(0.5 \sim 0.6]$ & 0.5 & 0.418 & 0.057 \\
$(0.6 \sim 0.7]$ & 0.5 & 0.373 & 0.061 \\
$(0.7 \sim 0.8]$ & 0.5 & 0.391 & 0.056 \\
$(0.8 \sim 0.9]$ & 0.5 & 0.378 & 0.058 \\
{$[0.1 \sim 0.9]$} & 0.5 & 0.391 & 0.058 \\
\hline
\end{tabular}

The NDVI-based prior BRDF knowledges is used to fit the corresponding simulated nadir observations according to NDVI, and the retrieved albedos are compared with the MODIS results (Figure 14). The nadir reflectance is also compared with the MODIS albedo to show the effect of the Lambertian assumption. The Lambertian assumption may produce a large error in the albedo at a solar zenith angle of $40^{\circ}$ with a relative uncertainty of $13.1 \%$. Albedos retrieved from NDVI-based prior BRDF and archetypal BRDF No. 3 are close and more accurate. The prior BRDF knowledge 
constrains the changes of retrieved BRDFs, and the albedos retrieved from prior BRDFs are limited to a reasonable range.

The random noise in the single nadir observation is completely transmitted to the albedo using this method. When the maximum random noise increases from $10 \%$ to $20 \%$, the relative uncertainty increases by approximately $3-4 \%$.

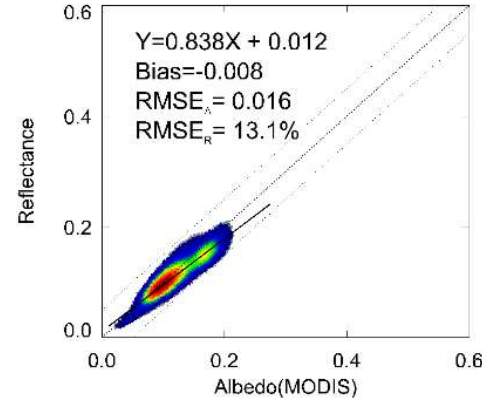

(a)

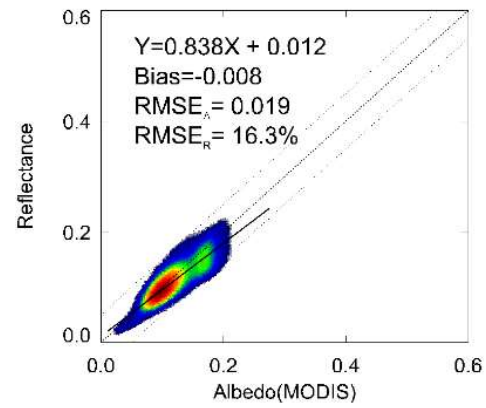

(d)

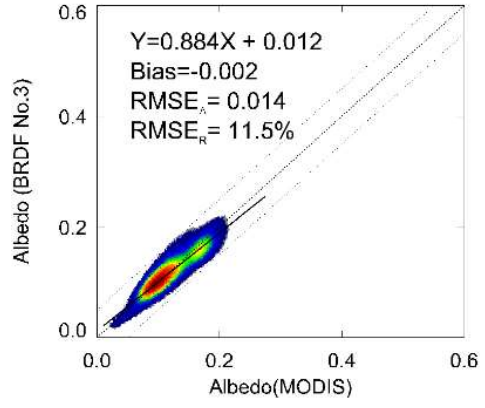

(b)

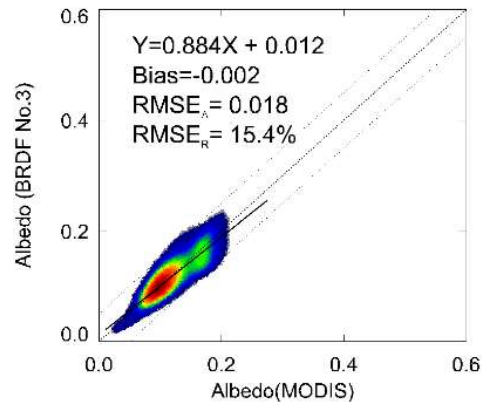

(e)

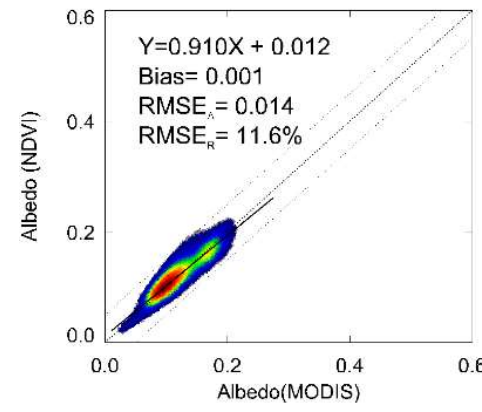

(c)

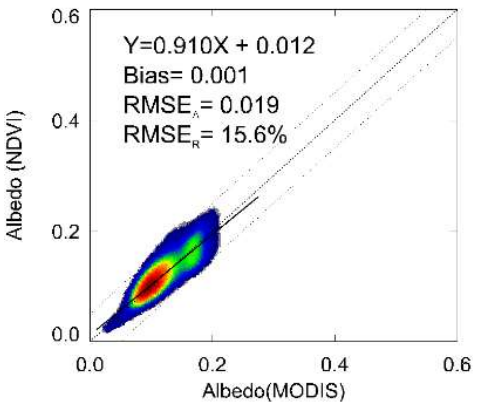

$(\mathbf{f})$

Figure 14. (a,d) Comparison of MODIS albedo with nadir reflectance, or $(\mathbf{b}, \mathbf{e})$ albedo retrieved from archetypal BRDF No. 3, and (c,f) NDVI-based prior BRDF. The maximum random noise is $10 \%$ for $(\mathbf{a}-\mathbf{c})$, and $20 \%$ for $(\mathbf{d}-\mathbf{f})$.

In addition, we examined the use of archetypal BRDFs in the albedo retrieval from non-nadir reflectance. Archetypal BRDF No. 3 is used to fit the directional reflectance with a viewing zenith angle of $30^{\circ}$ in the forward or backward direction to generate albedo. Figure 15 shows a comparison of these reflectances and retrieved albedos with MODIS albedos. The results show that the reflectance in the forward (backward) direction is significantly smaller (larger) than the MODIS albedo, with relative uncertainties of $23.3 \%$ and $27.2 \%$, respectively. However, the accuracy of the retrieved albedo based on archetypal BRDF No. 3 is greatly improved with a more than $10 \%$ reduction in the relative uncertainty, and the albedo basically meets the requirement for use in climate studies.

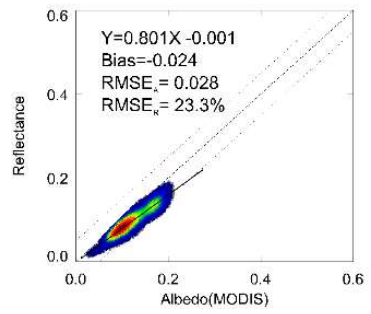

(a)

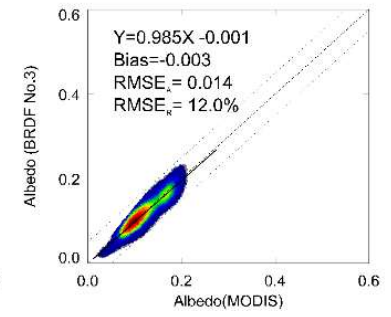

(b)

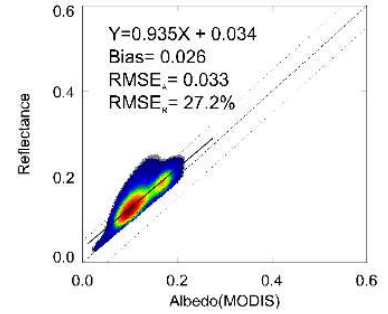

(c)

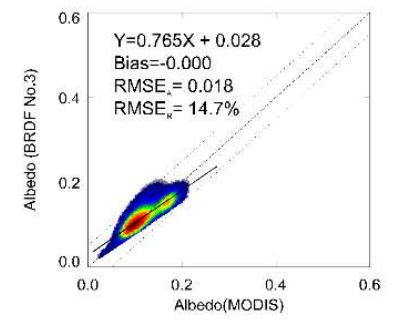

(d)

Figure 15. Density scatter plots of MODIS albedo and directional reflectance or corresponding albedo. $(\mathbf{a}, \mathbf{c})$ The directional reflectance in the forward direction and backward direction, respectively, with a view zenith angle of $30^{\circ}$. (b,d) Albedo based on archetypal BRDF No. 3 and directional reflectance in the forward and backward direction, respectively. 
The archetypal BRDF No. 3 is further applied to the simulated directional reflectance of tile h11v03 from 2009 day 185. Figure 16 shows the MODIS albedo and different directional reflectance simulated from the MODIS BRDF product and kernel driven BRDF model at a solar zenith angle of $40^{\circ}$. Three directional reflectances are simulated: The nadir reflectance and the reflectance with a view zenith of $30^{\circ}$ in the forward and backward directions. For validation purposes, we consider only the high-quality MODIS BRDF product over the tile. Figure 17 shows the albedo images retrieved from the directional reflectance and archetypal No. 3. Table 3 shows the corresponding mean values of these reflectances and albedos. These reflectances show significant differences from the MODIS albedo. The reflectance in the backward $30^{\circ}$ direction (0.155) is greater than the MODIS albedo (0.132), whereas the reflectance in the forward $30^{\circ}$ direction (0.104) is smaller than the MODIS albedo. The retrieved albedos based on archetypal BRDF No. 3 are more consistent with the MODIS albedo, and the mean albedo values are very close to one another. The results indicate that the intermediate archetypal BRDFs may be used to improve albedo retrieval from directional reflectance in the shortwave band.

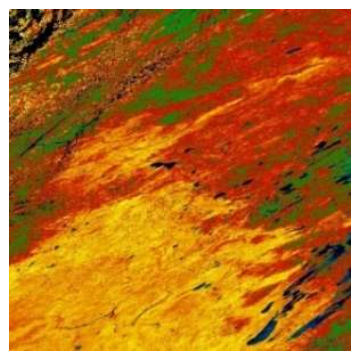

(a)

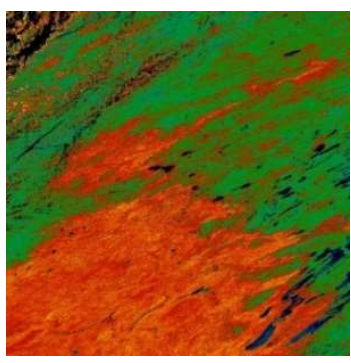

(b)

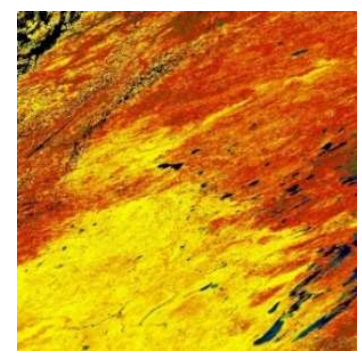

(c)

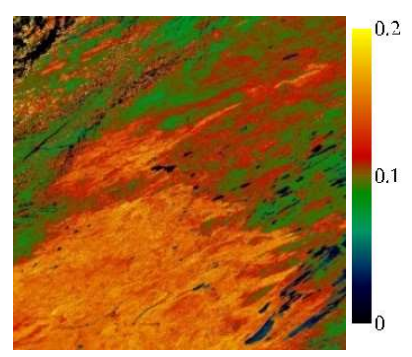

(d)

Figure 16. MODIS albedo (a), and simulated MODIS shortwave reflectance in the forward $30^{\circ}(\mathbf{b})$, and backward $30^{\circ}$ (c) direction, and in the nadir direction (d) at a solar zenith angle of $40^{\circ}$, based on the MODIS BRDF product of h11v03 from day 185, 2009.

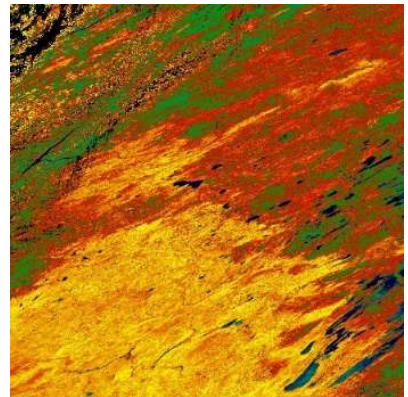

(a)

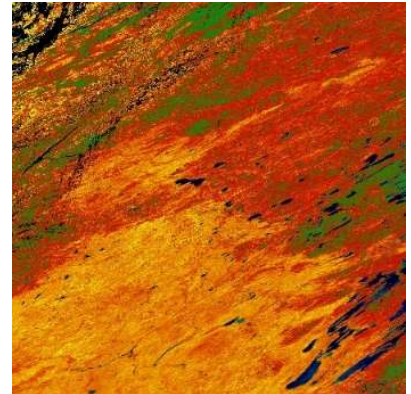

(b)

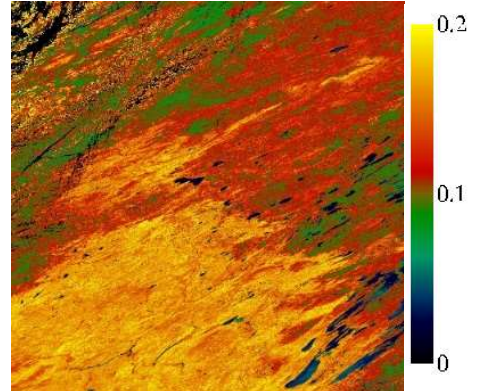

(c)

Figure 17. Albedo retrieved from archetypal BRDF No. 3 and directional reflectance in the (a) forward $30^{\circ}$, and (b) backward direction $30^{\circ}$, and (c) nadir direction at a solar zenith angle of $45^{\circ}$.

Table 3. The mean value of reflectance or albedo for the study area.

\begin{tabular}{cccc}
\hline Direction & Reflectance & Albedo (Arc No. 3) & MODIS Albedo \\
\hline Forward $30^{\circ}$ & 0.104 & 0.131 & \\
Backward $30^{\circ}$ & 0.155 & 0.129 & 0.132 \\
Nadir & 0.119 & 0.130 & \\
\hline
\end{tabular}

\section{Discussion}

This paper is an extension of previous studies [40], and in this study, an analysis of the reflectance anisotropy effect on albedo retrieval is presented. Based on AFX, which supports a BRDF-based classification of BRDF typology, the complex reflectance anisotropy can be classified, and the shortwave archetypal BRDFs were extracted from historical MODIS BRDF products. The archetypal BRDFs 
representativeness of the reflectance anisotropy was evaluated by calculating how well the archetypal BRDFs fit the MODIS BRDF within the corresponding BRDF archetype class.

The albedo retrieval accuracy from remotely sensed observations is jointly determined by the observation data and the BRDF model. An observational dataset with different viewing geometries can be simulated with the MODIS BRDF product and RTLSR in a forward model. In this study three observation conditions are considered: (1) Sufficient observations, (2) insufficient observations with a maximum view zenith angle of $20^{\circ}$, and (3) single directional observations. Then the archetypal BRDFs are used to fit the multi-angular observations or single directional observations, and eventually, the albedo is obtained. Since the BRDF anisotropy remains unchanged during the fitting process using the least squares method, the albedos retrieval from various archetypal BRDFs can indicate the reflectance anisotropy effect on albedo retrieval. The albedo based on the least RMSE method and multi-angular observations was also calculated. For single observations, prior BRDF knowledge, which was extracted from MODIS data at a 0.1 NDVI interval, was also used to calculate albedo.

When the observations are sufficient, albedos retrieved from various BRDF archetypes are broadly similar and all are consistent with the MODIS albedo. Meanwhile, the albedo retrieved from the least RMSE method shows the maximum accuracy. The results suggest that the reflectance anisotropy effect on the albedo retrieval from sufficient multi-angular observations is less significant. When multi-angular observations are insufficient, the reflectance anisotropy effect becomes non-trivial. The albedo will appear to be an evident bias when the prior BRDF and real BRDF show great differences. The bias might increase when the number of observations is fewer or the range of the viewing zenith angle is more concentrated. The albedo retrieved from the least RMSE method is also slightly unreliable, since insufficient observations cannot accurately indicate the BRDF shapes in the whole hemisphere.

For the nadir reflectance, first, the effect of the Lambertian assumption is studied based on archetypal BRDFs. The influence is determined by the surface reflectance anisotropy and solar zenith angle; when the solar zenith angle is small, and the geometric scattering is dominant, the Lambertian assumption tends to overestimate the land surface albedo. When the solar zenith angle is large and the volumetric scattering is dominant, the Lambertian assumption tends to underestimate the land surface albedo. Then, two albedos were retrieved from prior BRDF knowledge: (1) Archetypal BRDF No. 3, and (2) mean BRDF of data with a 0.1 NDVI interval. Nadir reflectance and all albedos were compared with the MODIS albedo. The results show that nadir reflectance is largely different from the MODIS albedo, due to the reflectance anisotropy effect. However, the albedos retrieved from prior knowledge at different solar zenith angles agree well with the MODIS albedo. The archetypal BRDF No. 3 is further used to generate the albedo of tile h11v03 from various single directional reflectances, and although the directional reflectance shows deviation from the MODIS albedo, the retrieved albedos remain highly consistent with the MODIS albedo.

The reflectance anisotropy is determined by the land surface structure. NDVI data are generally calculated from a single directional reflectance; thus, these data contain limited reflectance anisotropy information. We extract prior BRDF knowledge from MODIS data with a 0.1 NDVI interval, rather than from the homogenous pixels, since it is difficult to find pure pixels at the MODIS scale, especially for the forest area. This statistical approach method may be inappropriate in some respects, but it can still explain the feasibility of extracting prior knowledge from MODIS based on NDVI. The shape of prior BRDF knowledge based on NDVI is broadly similar, and the accuracy of the albedo retrieved from the NDVI-based prior knowledge shows no obvious improvement compared with the albedo retrieved from archetypal BRDF No. 3. The effectiveness of the NDVI in extracting prior BRDF knowledge from historical MODIS BRDF data is very limited.

The effect of the solar zenith angle and noise on albedo retrieval is also explored in this study. With the increase in solar zenith angle, the absolute difference between the MODIS albedo and albedos retrieved from different archetypal BRDFs tends to concentrate in a smaller range; that is, the reflectance anisotropy effect on the albedo gradually decreases. For the influence of noise, the least squares method can reduce the effect of random noise for multi-angular observations, whereas the noise can be directly 
transmitted into albedo for single conditions with a pronounced increase in relative uncertainty with an increase in random noise.

In this study, we employed the RTLSR model rather than the hotspot-adjusted version of the RTLSR model, because the hotspot effect has a small effect on the albedo retrieval from multi-angular observations [54] and the multi-angular samples used in this study are distributed near the cross-principle plane. However, the large difference in the small solar zenith angle suggests that the hotspot effect cannot be ignored for albedo retrieval from insufficient observations or single directional reflectance. All of the results described above are based on the specific area during the summer time, and further studies are needed to understand the generalizability of these findings to other seasons and locations.

Accurate estimation of surface albedo is a prerequisite for estimating the radiation budget at the surface with remotely sensed data. The albedo is the integration of BRDFs over the hemisphere. Although the prior BRDF may have certain differences from the real BRDF, the prior BRDFs constrain the change of BRDF in the retrieval process, and the resulting albedo can still be limited to a reasonable range, which may partly explain why different prior knowledge can obtain a reasonable result. However, when the reflectance anisotropy information in a specific direction must be used, such as normalizing the directional reflectance to the nadir direction or calculating the clumping index, this prior BRDF knowledge may be unrepresentative.

\section{Conclusions}

In this study, the reflectance anisotropy effect on albedo retrieval is evaluated using the MODIS BRDF data and various prior BRDFs. The shortwave band archetypal BRDFs were extracted and evaluated based on time series MODIS BRDF. These archetypal BRDFs were used to fit simulated observations with different viewing geometries using the least squares method. The difference between prior BRDF-based albedos and the MODIS albedo was used to quantify the effect. The following results were obtained.

(1) Six archetypal BRDFs are sufficient to summarize the reflectance anisotropy for quantifying the albedo retrievals in the shortwave band. The obtained archetypal BRDFs change from dome-shaped to bowl-shaped with increasing AFX values.

(2) For the multi-angular observations used in this study, albedos retrieved from various archetypal BRDFs and sufficient observations agree well with the MODIS albedo. The relative uncertainty caused by reflectance anisotropy is $<7.4 \%$. The reflectance anisotropy effect on albedo retrieval from insufficient observations is markedly increased, with a relative uncertainty $<16.2 \%$. The inappropriate BRDF can introduce up to $14 \%$ and $35.9 \%$ relative uncertainties for sufficient and insufficient observations, respectively. The least RMSE method acquired a more accurate result with a relative uncertainty of approximately $13.4 \%$ at a solar zenith angle of $40^{\circ}$. The reflectance anisotropy effect on albedo retrieval is non-trivial when the solar zenith angle is less than $30^{\circ}$.

(3) For the single directional reflectance, the Lambertian assumption could introduce a relative difference range from $-40 \%$ to $50 \%$ for albedo values. If the inappropriate prior archetypal BRDF is used, the relative uncertainty can reach up to $38.3 \%$ in the albedo at the $40^{\circ}$ solar zenith angle. Compared with the albedo retrieved from archetypal BRDF No. 3, the NDVI-based prior knowledge does not have any advantage in albedo retrieval, and the albedo of both methods has a relative uncertainty of approximately $11 \%$. The relative uncertainty increased approximately $3-4 \%$ when the maximum random noise increased from $10 \%$ to $20 \%$.

(4) The intermediate archetypal BRDFs (No. 3 and 4) can enable a reasonably accurate (8-15\%) estimation of surface albedo from insufficient multi-angular observations or single directional reflectance. Even if insufficient observations cannot provide adequate information and the directional reflectance shows a large difference from the MODIS albedo, the retrieved albedos 
based on archetypal BRDF No. 3 meet the requirements for use in climate studies. The albedo over tile h11v03 retrieved from a different directional reflectance and archetypal BRDF No. 3 is highly consistent with the MODIS albedo. The results indicate that this method is practical and effective for application to radiation budget studies, as many traditional satellite sensors do not provide multi-angle measurements.

Author Contributions: Conceptualization, H.Z. and Z.J.; Data curation, L.C., X.Z., Y.L. and D.Q.; Funding acquisition, Z.J.; Investigation, L.C.; Methodology, H.Z.; Supervision, Y.D. and T.C.; Writing—original draft, H.Z.; Writing-review \& editing, H.Z., Z.J., L.C., Y.L. and T.C.

Funding: This work was supported by the National Natural Science Foundation of China (Grant No. 41601348, 41571326 and 41471314) and the Research Foundation for the Doctoral Program of Tianjin Normal University (Grant No. 043-135202XB1620 and 043-135202XB1617).

Acknowledgments: The authors would like to thank NASA for providing MODIS data that are available online.

Conflicts of Interest: The authors declare no conflicts of interest.

\section{References}

1. Dickinson, R.E. Land surface processes and climate surface albedos and energy balance. Adv. Geophys. 1983, 25, 305-353.

2. Lahoz, W. Systematic Observation Requirements for Satellite-Based Products for Climate, 2011 Update, Supplemental Details to the Satellite-Based Component of the Implementation Plan for the Global Observing System for Climate in Support of the UNFCCC (2010 Update); World Meteorological Organization (WMO): Geneva, Switzerland, 2011.

3. Henderson-Sellers, A.; Wilson, M.F. Surface albedo data for climatic modeling. Rev. Geophys. 1983, 21, 1743-1778. [CrossRef]

4. Jacob, F.; Olioso, A. Derivation of diurnal courses of albedo and reflected solar irradiance from airborne polder data acquired near solar noon. J. Geophys. Res. Atmos. 2005, 110, D10104. [CrossRef]

5. Sellers, P.J. Remote Sensing of the Land Surface for studies Of Global Change; Report; NASA Goddard Space Flight Center: Greenbelt, MD, USA, 1993.

6. Roman, M.O.; Gatebe, C.K.; Shuai, Y.; Wang, Z.; Gao, F.; Masek, J.G.; He, T.; Liang, S.; Schaaf, C.B. Use of in situ and airborne multiangle data to assess modis- and landsat-based estimates of directional reflectance and albedo. IEEE Trans. Geosci. Remote Sens. 2013, 51, 1393-1404. [CrossRef]

7. Jacob, F.; Olioso, A.; Gu, X.F.; Su, Z.; Seguin, B. Mapping surface fluxes using airborne visible, near infrared, thermal infrared remote sensing data and a spatialized surface energy balance model. Agronomie 2002, 22, 669-680. [CrossRef]

8. Lucht, W.; Roujean, J.L. Considerations in the parametric modeling of brdf and albedo from multiangular satellite sensor observations. Remote Sens. Rev. 2000, 18, 343-379. [CrossRef]

9. Strahler, A.H.; Wanner, W.; Schaaf, C.B.; Li, X.; Hu, B.; Muller, J.P.; Lewis, P.; Barnsley, M.J. MODIS BRDF/albedo product: Algorithm theoretical basis document; NASA EOS-MODIS Doc.; Version 4.0; 1996. Available online: http:/ / modis-sr.ltdri.org/files/pdf/MODIS_BRDF.pdf (accessed on 12 October 2018).

10. Nicodemus, F.E.; Richmond, J.C.; Hsia, J.J.; Ginsberg, I.W.; Limperis, T. Geometrical Considerations and Nomenclature for Reflectance; National Bureau of Standards, US Department of Commerce: Washington, DC, USA, 1977.

11. Asner, G.P. Contributions of multi-view angle remote sensing to land-surface and biogeochemical research. Remote Sens. Rev. 2000, 18, 137-162. [CrossRef]

12. Lucht, W.; Schaaf, C.B.; Strahler, A.H. An algorithm for the retrieval of albedo from space using semiempirical brdf models. IEEE Trans. Geosci. Remote Sens. 2000, 38, 977-998. [CrossRef]

13. Roujean, J.-L.; Tanré, D.; Bréon, F.-M.; Deuzé, J.-L. Retrieval of land surface parameters from airborne polder bidirectional reflectance distribution function during hapex-sahel. J. Geophys. Res. Atmos. 1997, 102, 11201-11218. [CrossRef]

14. Li, X.; Strahler, A.H. Geometric-optical bidirectional reflectance modeling of the discrete crown vegetation canopy: Effect of crown shape and mutual shadowing. IEEE Trans. Geosci. Remote Sens. 1992, 30, $276-292$. [CrossRef] 
15. Ross, J.K. The Radiation Regime and Architecture of Plant Stands; Dr. W. Junk: Norwell, MA, USA, 1981; 392p.

16. Roujean, J.-L.; Leroy, M.; Deschamps, P.-Y. A bidirectional reflectance model of the earth's surface for the correction of remote sensing data. J. Geophys. Res. 1992, 97, 20455-20468. [CrossRef]

17. Walthall, C.L.; Norman, J.M.; Welles, J.M.; Campbell, G.; Blad, B.L. Simple equation to approximate the bidirectional reflectance from vegetative canopies and bare soil surfaces. Appl. Opt. 1985, 24, 383-387. [CrossRef] [PubMed]

18. Privette, J.L.; Eck, T.F.; Deering, D.W. Estimating spectral albedo and nadir reflectance through inversion of simple brdf models with avhrr/modis-like data. J. Geophys. Res. Atmos. 1997, 102, 29529-29542. [CrossRef]

19. Wanner, W.; Li, X.; Strahler, A.H. On the derivation of kernels for kernel-driven models of bidirectional reflectance. J. Geophys. Res. 1995, 100, 21077-21089. [CrossRef]

20. Jin, Y.; Schaaf, C.B.; Gao, F.; Li, X.; Strahler, A.H.; Lucht, W.; Liang, S. Consistency of modis surface bidirectional reflectance distribution function and albedo retrievals: 1. Algorithm performance. J. Geophys. Res. Atmos. 2003, 108, 4158. [CrossRef]

21. Barnsley, M.J.; Strahler, A.H.; Morris, K.P.; Muller, J.P. Sampling the surface bidirectional reflectance distribution function (BRDF): 1. Evaluation of current and future satellite sensors. Remote Sens. Rev. 1994, 8, 271-311. [CrossRef]

22. Li, X.; Gao, F.; Wang, J.; Strahler, A. A priori knowledge accumulation and its application to linear brdf model inversion. J. Geophys. Res. Atmos. 2001, 106, 11925-11935. [CrossRef]

23. Schaaf, C.B.; Gao, F.; Strahler, A.H.; Lucht, W.; Li, X.; Tsang, T.; Strugnell, N.C.; Zhang, X.; Jin, Y.; Muller, J.-P.; et al. First operational brdf, albedo nadir reflectance products from modis. Remote Sens. Environ. 2002, 83, 135-148. [CrossRef]

24. Martonchik, J.V.; Diner, D.J.; Kahn, R.A.; Ackerman, T.P.; Verstraete, M.E.; Pinty, B.; Gordon, H.R. Techniques for the retrieval of aerosol properties over land and ocean using multiangle imaging. IEEE Trans. Geosci. Remote Sens. 1998, 36, 1212-1227. [CrossRef]

25. Martonchik, J.V.; Diner, D.J.; Pinty, B.; Verstraete, M.M.; Myneni, R.B.; Knyazikhin, Y.; Gordon, H.R. Determination of land and ocean reflective, radiative, and biophysical properties using multiangle imaging. IEEE Trans. Geosci. Remote Sens. 1998, 36, 1266-1281. [CrossRef]

26. Leroy, M.; Deuze, J.L.; Breon, F.M.; Hautecoeur, O.; Herman, M.; Buriez, J.C.; Tanre, D.; Bouffies, S.; Chazette, P.; Roujean, J.L. Retrieval of atmospheric properties and surface bidirectional reflectances over land from polder/adeos. J. Geophys. Res. Atmos. 1997, 102, 17023-17037. [CrossRef]

27. Dong, Y.; Jiao, Z.; Ding, A.; Zhang, H.; Zhang, X.; Li, Y.; He, D.; Yin, S.; Cui, L. A modified version of the kernel-driven model for correcting the diffuse light of ground multi-angular measurements. Remote Sens. Environ. 2018, 210, 325-344. [CrossRef]

28. Zhang, X.; Jiao, Z.; Dong, Y.; Zhang, H.; Li, Y.; He, D.; Ding, A.; Yin, S.; Cui, L.; Chang, Y. Potential investigation of linking prosail with the ross-li brdf model for vegetation characterization. Remote Sens. 2018, 10, 437. [CrossRef]

29. Jiao, Z.; Zhang, X.; Bréon, F.M.; Dong, Y.; Schaaf, C.B.; Román, M.; Wang, Z.; Cui, L.; Yin, S.; Ding, A. The influence of spatial resolution on the angular variation patterns of optical reflectance as retrieved from modis and polder measurements. Remote Sens. Environ. 2018, 215, 371-385. [CrossRef]

30. Dong, Y.; Jiao, Z.; Yin, S.; Zhang, H.; Zhang, X.; Cui, L.; He, D.; Ding, A.; Chang, Y.; Yang, S. Influence of snow on the magnitude and seasonal variation of the clumping index retrieved from modis brdf products. Remote Sens. 2018, 10, 1194. [CrossRef]

31. Jiao, Z.; Dong, Y.; Schaaf, C.B.; Chen, J.M.; Román, M.; Wang, Z.; Zhang, H.; Ding, A.; Erb, A.; Hill, M.J. An algorithm for the retrieval of the clumping index (ci) from the modis brdf product using an adjusted version of the kernel-driven brdf model. Remote Sens. Environ. 2018, 209, 594-611. [CrossRef]

32. Deering, D.W.; Eck, T.F.; Banerjee, B. Characterization of the reflectance anisotropy of three boreal forest canopies in spring-summer. Remote Sens. Environ. 1999, 67, 205-229. [CrossRef]

33. Deering, D.W.; Eck, T.F.; Grier, T. Shinnery oak bidirectional reflectance properties and canopy model inversion. IEEE Trans. Geosci. Remote Sens. 1992, 30, 339-348. [CrossRef]

34. Kimes, D.S. Dynamics of directional reflectance factor distributions for vegetation canopies. Appl. Opt. 1983, 22, 1364-1372. [CrossRef] [PubMed]

35. Walthall, C.; Roujean, J.L.; Morisette, J. Field and landscape brdf optical wavelength measurements: Experience, techniques and the future. Remote Sens. Rev. 2000, 18, 503-531. [CrossRef] 
36. Franch, B.; Vermote, E.F.; Claverie, M. Intercomparison of landsat albedo retrieval techniques and evaluation against in situ measurements across the US SURFRAD network. Remote Sens. Environ. 2014, 152, 627-637. [CrossRef]

37. Shuai, Y.; Masek, J.G.; Gao, F.; Schaaf, C.B. An algorithm for the retrieval of 30-m snow-free albedo from landsat surface reflectance and modis brdf. Remote Sens. Environ. 2011, 115, 2204-2216. [CrossRef]

38. Strugnell, N.C.; Lucht, W. An algorithm to infer continental-scale albedo from avhrr data, land cover class, and field observations of typical brdfs. J. Clim. 2001, 14, 1360-1376. [CrossRef]

39. Bacour, C.; Breon, F.M. Variability of biome reflectance directional signatures as seen by polder. Remote Sens. Environ. 2005, 98, 80-95. [CrossRef]

40. Jiao, Z.; Hill, M.J.; Schaaf, C.B.; Zhang, H.; Wang, Z.; Li, X. An anisotropic flat index (afx) to derive brdf archetypes from modis. Remote Sens. Environ. 2014, 141, 168-187. [CrossRef]

41. Zhang, H.; Jiao, Z.; Dong, Y.; Li, X. Evaluation of brdf archetypes for representing surface reflectance anisotropy using modis brdf data. Remote Sens. 2015, 7, 7826. [CrossRef]

42. Jiao, Z.; Zhang, H.; Dong, Y.; Liu, Q.; Xiao, Q.; Li, X. An algorithm for retrieval of surface albedo from small view-angle airborne observations through the use of brdf archetypes as prior knowledge. IEEE J. Sel. Top. Appl. Earth Obs. Remote Sens. 2015, 8, 3279-3293. [CrossRef]

43. Zhang, H.; Jiao, Z.; Dong, Y.; Du, P.; Li, Y.; Lian, Y.; Cui, T. Analysis of extracting prior brdf from modis brdf data. Remote Sens. 2016, 8, 1004. [CrossRef]

44. Myneni, R.B.; Asrar, G.; Hall, F.G. A three-dimensional radiative transfer method for optical remote sensing of vegetated land surfaces. Remote Sens. Environ. 1992, 41, 105-121. [CrossRef]

45. Lewis, P.; Barnsley, M.J. Influence of the sky radiance distribution on various formulations of the earth surface albedo. Proc. Conf. Physical Measurement E Signatures Remote Sens. 1994, 707-715.

46. Román, M.O.; Schaaf, C.B.; Lewis, P.; Gao, F.; Anderson, G.P.; Privette, J.L.; Strahler, A.H.; Woodcock, C.E.; Barnsley, M. Assessing the coupling between surface albedo derived from modis and the fraction of diffuse skylight over spatially-characterized landscapes. Remote Sens. Environ. 2010, 114, 738-760. [CrossRef]

47. Liu, J.; Schaaf, C.; Strahler, A.; Jiao, Z.; Shuai, Y.; Zhang, Q.; Roman, M.; Augustine, J.A.; Dutton, E.G. Validation of moderate resolution imaging spectroradiometer (modis) albedo retrieval algorithm: Dependence of albedo on solar zenith angle. J. Geophys. Res. 2009, 114, D01106. [CrossRef]

48. Roman, M.O.; Schaaf, C.B.; Woodcock, C.E.; Strahler, A.H.; Yang, X.; Braswell, R.H.; Curtis, P.S.; Davis, K.J.; Dragoni, D.; Goulden, M.L.; et al. The modis (collection v005) brdf/albedo product: Assessment of spatial representativeness over forested landscapes. Remote Sens. Environ. 2009, 113, 2476-2498. [CrossRef]

49. Salomon, J.G.; Schaaf, C.B.; Strahler, A.H.; Gao, F.; Jin, Y.F. Validation of the modis bidirectional reflectance distribution function and albedo retrievals using combined observations from the aqua and terra platforms. IEEE Trans. Geosci. Remote Sens. 2006, 44, 1555-1565. [CrossRef]

50. Jin, Y.; Gao, F.; Schaaf, C.B.; Li, X.; Strahler, A.H.; Bruegge, C.J.; Martonchik, J.V. Improving modis surface brdf/albedo retrieval with misr multiangle observations. IEEE Trans. Geosci. Remote Sens. 2002, 40, 1593-1604.

51. Vermote, E.F.; Kotchenova, S. Atmospheric correction for the monitoring of land surfaces. J. Geophys. Res. Atmos. 2008, 113. [CrossRef]

52. Dong, Y.; Jiao, Z.; Zhang, H.; Bai, D.; Zhang, X.; Li, Y.; He, D. A visualization tool for the kernel-driven model with improved ability in data analysis and kernel assessment. Comput. Geosci. 2016, 95, 1-10. [CrossRef]

53. Liang, S. Narrowband to broadband conversions of land surface albedo i: Algorithms. Remote Sens. Environ. 2001, 76, 213-238. [CrossRef]

54. Jiao, Z.; Schaaf, C.B.; Dong, Y.; Román, M.; Hill, M.J.; Chen, J.M.; Wang, Z.; Zhang, H.; Saenz, E.; Poudyal, R. A method for improving hotspot directional signatures in brdf models used for modis. Remote Sens. Environ. 2016, 186, 135-151. [CrossRef]

(C) 2018 by the authors. Licensee MDPI, Basel, Switzerland. This article is an open access article distributed under the terms and conditions of the Creative Commons Attribution (CC BY) license (http:/ / creativecommons.org/licenses/by/4.0/). 